\title{
Microanatomy and paleohistology of the intercentra of North American metoposaurids from the Upper Triassic of Petrified Forest National Park (Arizona, USA) with implications for the taxonomy and ontogeny of the group
}

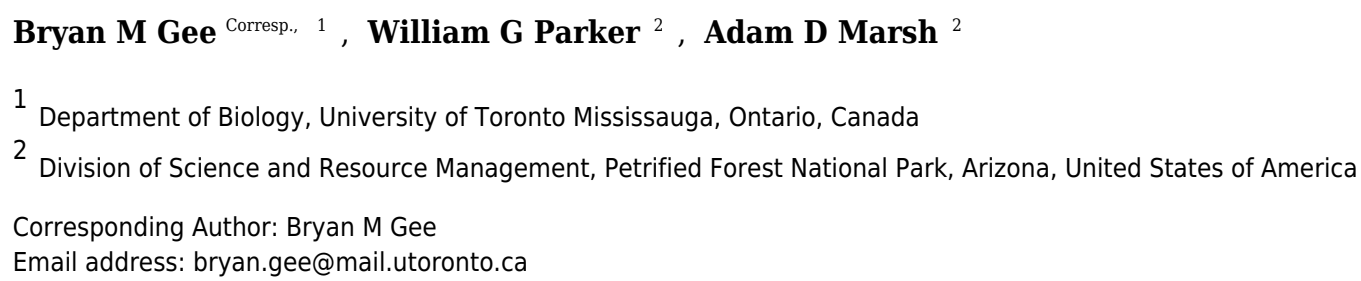

Metoposaurids are temnospondyl amphibians that are commonly recovered from the Chinle Formation deposits of North America. Two species, Koskinondon perfectus and Apachesaurus gregorii, are known from Petrified Forest National Park, AZ. Small, elongate intercentra are the single diagnostic postcranial characteristic of the smaller A. gregorii. However, a poor understanding of the earliest life stages of $K$. perfectus and other large metoposaurids makes it unclear whether the proportions of the intercentra are a diagnostic feature for species discrimination or whether they are influenced by ontogeny. Previous work on metoposaurid intercentra has proven that ontogenetic information can be extrapolated from histological analyses. Here we perform an analysis of the microanatomy and the histology of metoposaurid intercentra from Petrified Forest National Park to determine their ontogenetic maturity and in turn whether elongate intercentra are a reliable taxonomic feature for distinguishing North American metoposaurids. Our findings suggest that the elongate intercentra are the result of ontogenetic variation within a single large-bodied metoposaurid taxon rather than interspecific variation between two metoposaurids of vastly different adult sizes. These findings have significant implications for the taxonomy of North American metoposaurids and subsequently for interpretations of the Chinle Basin paleoenvironment. Furthermore, this study provides the first histological characterization of North American metoposaurid intercentra, thereby improving the understanding of vertebral ontogeny within Metoposauridae and offering new insights into the ecology of large metoposaurids. 
1 Microanatomy and paleohistology of the intercentra of North American metoposaurids

2 from the Upper Triassic of Petrified Forest National Park (Arizona, USA) with

3 implications for the taxonomy and ontogeny of the group

4

5 Bryan M. Gee ${ }^{1}$; William G. Parker²; Adam D. Marsh²

$6{ }^{1}$ Department of Biology, University of Toronto Mississauga, ON, Canada

7 2Division of Science and Resource Management, Petrified Forest National Park, AZ, USA

8

9 Corresponding author:

10 Bryan M. Gee

11

12

Corresponding email: bryan.gee@mail.utoronto.ca

13

14

15

16

17

18

19

20

21

22

23

24

25

26

27

28

29

30

31 


\section{Abstract}

33 Metoposaurids are temnospondyl amphibians that are commonly recovered from the Chinle

34 Formation deposits of North America. Two species, Koskinondon perfectus and Apachesaurus

35

36

37

38

39

40

41

42

43

44

45

46

47

48

49

50

51

52

\section{Introduction}

54 Metoposaurids are Late Triassic temnospondyl amphibians with a global distribution and are 55 gregorii, are known from Petrified Forest National Park, AZ. Small, elongate intercentra are the single diagnostic postcranial characteristic of the smaller A. gregorii. However, a poor understanding of the earliest life stages of $K$. perfectus and other large metoposaurids makes it unclear whether the proportions of the intercentra are a diagnostic feature for species discrimination or whether they are influenced by ontogeny. Previous work on metoposaurid intercentra has proven that ontogenetic information can be extrapolated from histological analyses. Here we perform an analysis of the microanatomy and the histology of metoposaurid intercentra from Petrified Forest National Park to determine their ontogenetic maturity and in turn whether elongate intercentra are a reliable taxonomic feature for distinguishing North American metoposaurids. Our findings suggest that the elongate intercentra are the result of ontogenetic variation within a single large-bodied metoposaurid taxon rather than interspecific variation between two metoposaurids of vastly different adult sizes. These findings have significant implications for the taxonomy of North American metoposaurids and subsequently for interpretations of the Chinle Basin paleoenvironment. Furthermore, this study provides the first histological characterization of North American metoposaurid intercentra, thereby improving the understanding of vertebral ontogeny within Metoposauridae and offering new insights into the ecology of large metoposaurids. some of the most commonly recovered fossils from freshwater depositional settings (e.g., Hunt, 1993). They are characterized by dorsoventrally-flattened skulls with anteriorly-positioned orbits, a highly ossified skeleton, and an adult size in excess of two meters in most taxa (Colbert \& Imbrie, 1956). There are presently three accepted taxa of metoposaurids in North America: two of large size, Koskinonodon perfectus and "Metoposaurus" bakeri, and one of small size, Apachesaurus gregorii (Case, 1922, 1931; Branson \& Mehl, 1929; Hunt, 1993; Mueller, 2007).

1 The taxonomy of metoposaurids, particularly the North American taxa, is in need of revision, 2 hence the indeterminate affinities of " $M$." bakeri, but such an analysis is beyond the scope of 
63 this paper. Koskinonodon perfectus and A. gregorii have a wide distribution in the southwestern

64 United States, including Arizona, New Mexico, and Texas, while “M." bakeri is mainly

65

66

67

68

69

70

71

72

73

74

75

76

77

78

79

80

81

82

83

84

85

86

87

88

89

90

91

92

93

restricted to Texas, with a single juvenile specimen from Nova Scotia (Hunt \& Lucas, 1993; Long \& Murry, 1995; Heckert \& Lucas, 2002; Parker \& Martz, 2011). It is worth noting that neither A. gregorii nor any other diminutive species of metoposaurid is known outside of North America (Long and Murry, 1995; Spielmann \& Lucas, 2012).

Both $K$. perfectus and A. gregorii are commonly recovered from the Chinle Formation exposures of Petrified Forest National Park (PEFO), AZ, USA. Koskinonodon perfectus is common in the lower units within the Chinle Formation (the Blue Mesa Member and lower part of the Sonsela Member) and is rare in the upper units (the upper part of the Sonsela Member and the Petrified Forest Member) (Hunt \& Lucas, 1993; Heckert \& Lucas, 2002; Martz and Parker, 2010; Parker \& Martz, 2011). Apachesaurus gregorii demonstrates the opposite pattern of stratigraphic distribution (Parker and Martz, 2011). Although $K$. perfectus is known from extensive amounts of cranial and postcranial material, including several dozen well-preserved skulls, the vast majority of material ascribed to A. gregorii consists of isolated, elongate intercentra that are considered diagnostic of the taxon (Hunt, 1993; Long \& Murry, 1995). The original diagnosis of $A$. gregorii by Hunt (1993:81-85) designated a diameter-to-length ratio of less than 0.8 as "elongate." However, the methodology used by Hunt (1993) to measure intercentra was poorly described, no data were presented to support the use of 0.8 as a quantitative threshold, and this metric was not included in the amended diagnosis of Spielmann \& Lucas (2012). We also note that elongate intercentra are not exclusive to this taxon, as they are also known in the large metoposaurid Dutuitosaurus ouazzoui (Dutuit, 1976; Hunt, 1993). Furthermore, although the diagnosis of $A$. gregorii includes a total of eleven cranial traits, the entire set can only be confirmed in the holotype specimen, and most other referred specimens preserve only a few of the diagnostic features (Spielmann \& Lucas, 2012). Finally, whereas size has frequently been used as an informal characteristic in identifying specimens (A. gregorii being significantly smaller than all other metoposaurid taxa), this is not a reliable metric given the role of ontogeny in changing body size (e.g., Horner, de Ricqlès \& Padian, 1998; Steyer et al., 2004; Horner \& Goodwin, 2009; Werning, 2012; Konietzko-Meier \& Sander, 2013). This is further confounded by the absence of a preserved complete growth series for North American metoposaurids, particularly with respect to the earliest life stages. Among the dozens of known 
94 skulls of $K$. perfectus, only two ascribed to juvenile specimens have been described (Zanno et al., 95 2002; Gee \& Parker, in press).

Although $A$. gregorii has been interpreted to be a small yet mature metoposaurid taxon, it

97 remains unclear whether the diagnostic features of the taxon, such as the shallow otic notches

98 and the elongate intercentra, are the product of speciation or if they are merely a

99 misinterpretation of features influenced by ontogeny in large metoposaurids. Such a possibility is

100 rarely considered in determining whether small metoposaurid specimens are skeletally mature

101 individuals of $A$. gregorii, as argued by Hunt (1993), or skeletally immature individuals of a

102 large metoposaurid such as K. perfectus. Although Hunt (1993) claimed that A. gregorii

103 represents a small yet mature taxon, many of the arguments rely heavily on external morphology

104 and a scant sample of juvenile metoposaurid specimens, and its ontogenetic maturity has never

105 been confirmed by more informative methods such as histological analyses. Accordingly, the

106 diagnosis of $A$. gregorii, which relies heavily on elongate intercentra given their prevalence in

107 depositional settings, is tentative in the absence of multiple specimens that can confirm more of

108 the informative cranial features or that can clearly associate elongate intercentra with diagnostic

109 cranial material. In this study, we focus on analyzing the histology and microanatomy of the

110 single diagnostic postcranial trait of $A$. gregorii, elongate intercentra. The goal of the analysis is

111 to elucidate additional ontogenetic information beyond that of the external morphology to better

112 determine whether $A$. gregorii represents a small, mature metoposaurid or if it may in fact be an

113 early ontogenetic stage of a large metoposaurid such as K. perfectus. If $A$. gregorii were indeed a

114 significantly smaller metoposaurid, we would expect to find histological and anatomical markers

115 of relative maturity (e.g., high degree of secondary remodeling, low abundance of calcified

116 cartilage, presence of annuli with LAGs) in the diagnostic intercentra.

117

118 Bone histology is a common method used to study ontogeny in a variety of extinct taxa, often by 119 comparison to extant members of these clades (summarized in Padian, 2013). Although the 120 majority of paleohistological inquiries have centered on amniotes, several analyses have focused 121 on temnospondyls. Most of these studies focus on long bones (e.g., Damiani, 2000; Konietzko-

122 Meier \& Schmitt, 2013; Konietzko-Meier, Shelton, \& Sander, 2015; Sanchez et al., 2010a;

123 Sanchez \& Schoch, 2013; McHugh, 2014, 2015), as is common with other vertebrate clades, but 124 other portions of the skeleton, such as osteoderms (e.g., Witzmann \& Soler-Gijon, 2010), the 
125 dermal sculpting of the skull and pectoral elements (e.g., Witzmann, 2009) and teeth (e.g.,

126 Warren \& Davey, 1992; Warren \& Turner, 2005) have also been examined. Many of the early

127 histological analyses of metoposaurids utilized material of the European Metoposaurus and the

128 Moroccan Dutuitosaurus (e.g., Dutuit, 1976, Gross, 1934; de Ricqlès, 1975, 1978, 1979), and

129 more recent studies have continued to utilize these genera for the study of long bones and cranial

130 bones in the Polish taxon Metoposaurus krasiejowensis (Konietzko-Meier \& Klein, 2012;

131 Konietzko-Meier \& Sander, 2013; Gruntmejer, Konietzko-Meier, \& Bodzioch, 2016) and long

132 bones of Dutuitosaurus (Steyer et al., 2004; Sanchez et al., 2010b). Less attention has been

133 directed toward the North American taxa (e.g., de Ricqlès, 1981; Warren \& Davey, 1992).

134 Furthermore, histological studies of temnospondyl intercentra have been performed only a

135 handful of times (e.g., Enlow \& Brown, 1956; Ray, Mukherjee, \& Bandyopadhyay, 2009;

136 Mukherjee, Ray \& Sengupta, 2010; Konietzko-Meier, Danto \& Gądek, 2014; Danto, Witzmann

$137 \&$ Fröbisch, 2016), and the only previous examination of metoposaurid intercentra was

138 conducted on the European taxon Metoposaurus krasiejowensis (Konietzko-Meier, Bodzioch \&

139 Sander, 2013). Therefore, the study of North American metoposaurid intercentra is important for

140 augmenting existing morphological and histological data that can be used in comparisons of

141 metoposaurid paleoecology and ontogeny. Metoposaurid intercentra spanning a wide size range

142 are commonly recovered elements at PEFO, making them more accessible for histology than the

143 relatively rare limb elements. This study seeks to provide an alternative approach to comparisons

144 of external morphology in order to evaluate the potential for metoposaurid intercentra

145 proportions to be influenced by ontogeny rather than speciation.

146

147 Keywords: metoposaurid, paleohistology, ontogeny, intercentra, vertebra

148 Institutional Abbreviations: NMMNH: New Mexico Museum of Natural History and Science, 149 Albuqerque, NM, USA; PEFO: Petrified Forest National Park, AZ, USA; UOPB, University of 150 Opole, Department of Biosystematics, Opole, Poland.

151

152 Materials and Methods.

153 Selection of specimens

154 All of the samples specimens were collected from the Late Triassic sedimentary rocks of the

155 Chinle Formation at Petrified Forest National Park, AZ, USA (Fig. 1-2). Metoposaurids are 
156 found throughout three units of the Chinle (the Blue Mesa Member, Sonsela Member, and

157 Petrified Forest Member), but there are disparate relative abundances of large and small

158 metoposaurids throughout the stratigraphic column (Parker \& Martz, 2011). Eight of the ten

159 elements were selected with the goal of sampling a pair of intercentra from the same

160 stratigraphic horizon, if not the same locality: one intercentrum of shortened proportions

161 normally referred to $K$. perfectus and one intercentrum of elongate proportions comparable to

162 those normally referred to A. gregorii (Table 1, Fig. 1-2). As noted in the introduction, the term

163 'elongate' is not quantitatively defined in the most recent diagnosis of A. gregorii (Spielmann \&

164 Lucas, 2012); therefore, our selection of specimens typical of A. gregorii was based on

165 specimens that have been figured by past authors (e.g., Hunt, 1993; Long \& Murry, 1995;

166 Spielmann \& Lucas, 2012).

167 Elements are assigned to the same specimen number on the basis of physical proximity

168 during collection and general taxonomic identity and should not be interpreted to mean that the

169 elements are from the same individual. We have created letter designations for multi-element

170 collection numbers for the purpose of this study (Table 1). Detailed locality information is on file

171 in the archives at Petrified Forest National Park and is available to qualified researchers. PEFO

1724826 and PEFO 38726 are from locality PFV 122 in the Blue Mesa Member (Fig. 1-3). PEFO

17338645 is from PFV 040 in the Petrified Forest Member (Fig. 1-3). PEFO 36874 and PEFO 16696

174 (two and three intercentra, respectively) are from a locality (PFV 215) in the Petrified Forest

175 Member (Fig. 1-3). The final two intercentra, belonging to PEFO 35392 (also from PFV 215),

176 were selected because of their association with a skull of a small metoposaurid that was

177 interpreted to be a juvenile K. perfectus (Gee \& Parker in press; Fig. 1-3). PEFO 4826, PEFO

178 36874a, and PEFO 16696a are of a typical size and proportion for A. gregorii (Fig. 3). PEFO

17938726 is typical for K. perfectus (Fig. 3). Several other elements, although relatively small

180 compared to the largest known intercentra of the taxon, are of proportions closer to those of $K$.

181 perfectus; these include: PEFO 38645 PEFO 36874b, PEFO 16696c, and PEFO 35392 (Fig. 3).

182 PEFO $16696 \mathrm{~b}$ is the most taxonomically ambiguous, as it is nearly identical in size to PEFO

1834826 but is also of different proportions and morphology (Fig. 3). Specimens were measured

184 using the same standards as Konietzko-Meier, Bodzioch \& Sander (2013) (Fig. 4A). The overall

185 size range of the elements sampled in this study (mediolateral width between $9.81 \mathrm{~mm}$ and 55.32 
$186 \mathrm{~mm}$ ) is comparable to that sampled by Konietzko-Meier, Bodzioch \& Sander (2013), which

187 ranged from 20.1 to $71 \mathrm{~mm}$ (Table 1 ).

188

189 Classification of specimens' axial position

190 Because North American metoposaurids, especially those from PEFO, are rarely articulated,

191 determining the exact serial position of the studied vertebrae remains difficult. Vertebrae are

192 placed using previously-outlined criteria (Sulej, 2007), but it should be noted that these criteria

193 were used in the description of $M$. krasiejowensis and it remains unknown what differences may

194 exist in the vertebral column between the European and North American taxa, especially in the

195 absence of preserved neural or haemal arches. Additionally, the determination of axial position

196 in M. krasiejowensis was made by comparison to the Moroccan metoposaurid Dutuitosaurus

197 ouazzoui, in which elongate intercentra more comparable to A. gregorii than to other

198 metoposaurids are known (Dutuit, 1976; Sulej, 2007). Finally, intraspecific variation in North

199 American metoposaurids is poorly known; thus the serial position of smaller intercentra is the

200 most tentative.

201

202 Thin section preparation and imaging

203 The intercentra were first cleaned using a toothbrush and water to remove excess matrix before

204 being consolidated with Paraloid B-72 (Rohm and Haas) dissolved in acetone. All specimens

205 were molded and casted according to National Park Service museum standards (National Park

206 Service, 2007), with Carbowax (molecular weight 4000; Dow) added to stabilize cracks and

207 other fragile areas. After creating two-part molds using Platsil 73-25 silicone rubber, the

208 Carbowax was removed using a brush and warm water. All specimens were impregnated in a

209 polyester resin mixture of Castolite ${ }^{\mathrm{TM}} \mathrm{AC}$ and hardener (Eager Polymers) at a ratio of $1 \mathrm{oz}$ of

210 Castolite $^{\mathrm{TM}}$ to 12 drops of hardener. The specimens were placed in a vacuum chamber to

211 evacuate gas from the resin and then allowed to cure for a minimum of 24 hours. Because the

212 primary focus of the study was to assess the ontogenetic stage of various intercentra to determine

213 whether small, elongate intercentra ascribed to $A$. gregorii belonged to juveniles of $K$. perfectus,

214 we initially focused on sagittal cuts (down the midline in the anteroposterior axis) (Fig. 4B), but

215 we subsequently made transverse (mediolateral axis) sections of all specimens (Fig. 4C). All

216 specimens were cut using an automated IsoMet 1000 Precision Saw (Buehler). The cut surface of 
217 the desired block and its respective thin section were prepared by polishing each with a 600-

218 mesh silicon carbide on glass plates. Both surfaces were rinsed with ethanol and then attached to 219 plexiglass slides using Scotch-Weld Instant Adhesive (CA40; 3M). The sections were allowed to 220 dry for a minimum of 1 hour. All specimens except PEFO 38726 were cut to a height of $0.7 \mathrm{~mm}$ 221 using the IsoMet 1000 Precision Saw. PEFO 38726 was too large to be cut by the automatic saw, 222 so it was cut manually with a larger saw fitting for the IsoMet. All specimens were polished in 223 the following sequence: Hillquist 1010 grinding cup, 600-mesh grit, 1000-mesh grit, and 1224 micron grit. PEFO 38726 was polished on a 600-mesh lap wheel before polishing on the 225 Hillquist to remove uneven surfaces from the manual cut. The thin sections were gradually 226 ground down with repeated examination under a compound microscope to evaluate their optical 227 clarity. All polishing after the Hillquist step was done manually on glass plates. Thin sections 228 were imaged on a Nikon Instruments AZ100 Multizoom microscope fitted with AZ-Plan Apo $2290.5 \mathrm{x}$ and AZ-Fluor 5x objective lenses, an AZ-RP rotatable polarizer plate, and a DS-Fi2 digital 230 camera mount. NIS-Elements imaging software was used for this study.

\section{Results}

233 General microanatomy and histology (Fig. 5-7)

234 Overall, the microanatomy and histology of the intercentra sampled are very similar to those that 235 were described for Metoposaurus krasiejowensis (Konietzko-Meier, Bodzioch \& Sander, 2013).

236 The microanatomy of the sampled intercentra is consistent within the sample regardless of size 237 or any variation in axial position. Nearly the entire element is made of endochondral and 238 periosteal trabecular bone; lamellar bone is found only in thin layers deposited within the 239 vascular canals and in the compact annulus at the ventral margin in mature individuals. In 240 sagittal profile, most of this tissue is endochondral bone that is found at the dorsal, anterior, and 241 posterior margins in all specimens and at the ventral margin in more ontogenetically immature 242 individuals (Fig. 5A,C). A periosteal cortex is located in the ventral region of the element with 243 the corners near the anteroventral and posteroventral corners and the apex terminating near the 244 geometrical center (Fig. 5A,C). In transverse profile, the endochondral bone is found in the 245 dorsal and more interior regions of the element (Fig. 5B,D). The periosteal cortex is found at the 246 ventral margin and extends up the lateral margins in this profile (Fig. 5B,D). Konietzko-Meier,

247 Bodzioch, \& Sander (2013) noted the presence of periosteal bone in the dorsal half of a presacral 
248 intercentrum and the atlas in transverse section, but an atlas was not sampled in this study, and

249 no periosteal bone was definitively noted in the dorsomedial region of the presacral intercentra

250 (PEFO 16696a, PEFO 38645). Within the periosteal region, the trabeculae are distributed in an

251 orderly set of layers that are parallel to the ventral margin of the intercentrum, usually giving

252 them a slightly convexity (Fig. 5-6). In the smallest intercentra, the periosteal region is semi-

253 circular in sagittal profile owing to the presence of an open notochordal canal (Fig. 5A, 8-9). In

254 larger intercentra, the cortex is triangular with an apex that terminates near the geometric center

255 (Fig. 5C), with the highest apex found in the largest specimen. In sagittal view, the periosteal

256 region is divided from the remainder of the intercentrum by a prominent line of trabeculae that

257 are oriented at a consistent oblique angle that contrasts with the otherwise irregularly distributed

258 endochondral trabeculae (Fig 5A,C). The division of periosteal and endochondral bone is less

259 defined near the apex. Many of the specimens sampled by this study have been partially infilled,

260 and in some cases slightly damaged, by secondary precipitation of carbonate minerals. In most

261 specimens, the minerals appear to have precipitated within the existing internal structures,

262 although some parallel layers of the periosteal cortex have been lost in larger specimens.

263 The histological nature of the metoposaurid intercentrum is more variable within the

264 sample, differing primarily in the relative abundance and distribution of various features such as

265 calcified cartilage and the deposition of primary lamellar bone rather than the presence or

266 absence of these features. Although the majority of each intercentrum is made of trabecular bone,

267 more compact lamellar bone can be found deposited inside of vascular canals and in the outer

268 layers of the periosteal cortex. The trabeculae form a denser network with smaller intertrabecular

269 spaces at the articular faces whereas the spacing in the interior and dorsal regions is greater (Fig.

270 10). The most ventral portions of the periosteal cortex are parallel-layered in both sagittal and

271 transverse profiles, a structure that results from the large numbers of vascular canals oriented in

272 the anteroposterior axis. The external lamellar portion of the cortex (annulus) is poorly

273 vascularized and more compact. Lines of arrested growth (LAGs) can be identified in this layer

274 in the largest specimen (Fig. 11G). The external periosteal trabeculae form a layered matrix that

275 is oriented parallel to the external margins, but the interior portions of the cortex consist of large

276 erosion cavities with irregular networks of trabeculae. These periosteal trabeculae transition to

277 endochondral trabeculae in the innermost portions of the intercentrum. In relatively immature

278 individuals, the trabeculae are frequently associated with calcified cartilage at both the margins 
279 and in the interior of the element. In more mature individuals, the cartilage decreases in

280 abundance in conjunction with an increase in secondary bone deposition, particularly within the

281 interior endochondral region. Calcified cartilage persists throughout the entire sample, but

282 becomes rare in the largest intercentrum (Fig. 12). Osteocyte lacunae are primarily circular

283 except in the compact layers of the periosteal cortex in which they are flattened and more

284 elongate. Most intercentra feature large open cavities of various degrees of penetration into the

285 interior of the element that are distributed randomly along the external periosteal margin. These

286 are probably nutrient foramina in which part of the canal is exposed two-dimensionally,

287 accounting for the variable depth and morphology across the sample. Sharpey's fibers can be

288 found at the ventrolateral margins.

289

290 Detailed descriptions

291 The following descriptions are listed in order by size, as in Figures 6 and 7. Because the primary 292 goal of this study was to assess the ontogenetic maturity of small, elongate intercentra normally 293 assigned to $A$. gregorii, the description focuses mainly on features that have been recognized as 294 ontogenetically informative in M. krasiejowensis (Konietzko-Meier, Bodzioch, \& Sander, 2013). 295

296 PEFO 36874a (Fig. 6A, 7A): In sagittal profile, both anterior and posterior articular faces are 297 markedly amphicoelous. The notochordal canal, which extends longitudinally in the 298 anteroposterior axis, is partially infilled with secondary minerals but was also in the process of 299 closure at the time of death via deposition of cartilage into the canal from the dorsal and ventral 300 halves (Fig. 8C-D). Owing to the presence of the notochordal canal, the periosteal cortex is semi301 circular in shape and originates at the ventral corners (Fig. 9A). The cortex features a large 302 number of vascular canals that are filled with thin primary depositions of lamellar bone. In 303 comparison to larger, presumably more mature intercentra, the total thickness of this lamellar 304 bone is relatively thin. There is no evidence of a compact lamellar annulus in the outer margin of 305 the cortex. The apex of the periosteal cortex is poorly defined in sagittal profile. The cortex is 306 overall highly vascularized. A large nutrient foramen is located slightly ventral to the periosteal307 endochondral margin; a possible second, similarly sized foramen is located between these two 308 landmarks. A significantly smaller foramen is found on the ventrolateral surface. The closure of 309 the notochordal canal is a feature not seen in any of the other sampled specimens. The majority 
310 of the deposition into the canal is cartilaginous, although some trabeculae can be seen forming

311 closer to the distinct margins that bound the canal. The deposition appears to be originating close

312 to the geometric center and from both sides, although the relative contribution from the dorsal

313 half appears to be greater.

314 The endochondral trabeculae are thickest at the articular surfaces and the ventral half of

315 the element. They are thinner and more widely spaced in the dorsal endochondral region and

316 toward the geometric center (Fig. 10A). The notochordal canal is bordered on the margins by a

317 dorsoventrally short layer of thick endochondral trabeculae that separates it from the periosteal

318 cortex in the ventral half and from the thinner endochondral network in the dorsal half; the

319 thickness of this layer is approximately the same on both margins and slightly thinner than that at

320 the articular surfaces. Secondary remodeling can be found in the trabeculae at the margin

321 between the periosteal cortex and the endochondral trabecular network, particularly at the dorsal

322 margin of the cortex where this margin becomes less clearly defined, but secondary osteons are

323 extremely rare and found only in the interior of the element and at the precise margins. The vast

324 majority of the trabecular network is primary bone. Calcified cartilage is pervasive at both the

325 margins and the interior of the element.

326

327 PEFO 16696a (Fig. 6B, 7B): The microanatomy and histology of PEFO 16696a are similar to

328 those of PEFO 36874a. The most significant differences pertain to the density of the dorsal

329 endochondral network, the vascularization of the periosteal cortex, and the overall quality of

330 preservation. As with the other small intercentra, the total deposition of lamellar bone within

331 vascular canals is relatively thin, and there is no compact lamellar annulus. The only difference

332 in the cortex from that of the other two specimens is a greater spacing between the parallel layers

333 when viewed in transverse profile; no such difference is apparent in sagittal profile. There is no

334 evidence of closure of the notochordal canal as in PEFO 36874a (Fig. 8A). As with the other two

335 specimens, the notochordal canal is bounded on both margins by a short layer of thick

336 endochondral trabeculae.

337 The spacing between the endochondral trabeculae is the greatest of the sampled

338 specimens and does not appear to be a feature of damage from diagenesis, at least in sagittal

339 profile (Fig. 10B). In this view, only the dorsal portion of the periosteal cortex is noticeably more

340 damaged than in PEFO 36874a where some of the parallel layers have been completely 
341 destroyed by coarse-grained secondary carbonates. However, in transverse profile, nearly all of

342 the internal bone has been destroyed by similarly coarse carbonates, preserving only a sparse

343 scattering of endochondral trabeculae in the dorsal portion of the intercentrum, the trabeculae

344 immediately surrounding the notochordal canal, and externalmost layers of the periosteal cortex.

345 Enough of the obliquely-oriented trabeculae are preserved to identify the distinct margin between

346 endochondral and periosteal domains. A small degree of secondary remodeling can be identified,

347 particularly at this margin and around the notochordal canal, but its relative abundance compared

348 to primary deposition cannot be resolved in transverse profile. In sagittal profile, secondary

349 remodeling and secondary osteons are relatively rare. At least one nutrient foramen can be

350 identified in transverse profile in the cortex, but the extent of penetration is indeterminate. Where

351 trabeculae are preserved, calcified cartilage is pervasive, including at both the center near the

352 notochordal canal and at the outer margins.

353

354 PEFO 4826 (Fig. 6C, 7C): The microanatomy and histology of PEFO 4826 are nearly identical

355 to that of PEFO 36874a and PEFO 16696a, with the only major differences pertaining to the

356 overall degree of vascularization in the periosteal cortex, the density of the endochondral

357 trabecular network, and the partial closure of the notochordal canal. The periosteal cortex is

358 semi-circular, originating at the ventral corners, is comprised of highly vascularized parallel

359 layers with thin depositions of lamellar bone within the vascular canals, grades into

360 endochondral trabeculae dorsally, and is lacking in a compact lamellar annulus. The apex is more

361 clearly defined than in the other two specimens (Fig. 9C). The notochordal canal is infilled with

362 secondary minerals and shows no evidence of closure (Fig. 8B). Its margins are nearly smooth

363 and there is no evidence of tissue deposition into the canal. In transverse profile, two to three

364 open cavities are present in the periosteal cortex; they are relatively shallow, terminating around

365 the transition to large erosion cavities in the interior of the intercentrum. Two of these cavities

366 also appear to extend a short distance horizontally between the parallel layers of the periosteal

367 matrix after penetrating to the same depth within the element. Sharpey's fibers can be identified

368 on the ventrolateral surface; they may be more widely spread, but the externalmost layer of the

369 cortex appears to have been damaged in many areas.

370 The endochondral region of this specimen is nearly identical to that of the other two

371 small intercentra in being thickest at the articular surfaces and thinnest in the dorsal region. It 
372 differs only in having a slightly less disperse trabecular network in the dorsal portion of the

373 element (Fig. 10C). As with those intercentra, secondary remodeling and secondary osteons are

374 very rare, and calcified cartilage is widespread throughout the element, though to a lesser degree

375 than in the other two specimens.

376

377 PEFO 16696b (Fig. 6D, 7D): This specimen is the smallest intercentrum that shows no clear

378 evidence of a notochordal canal. As a result of the absence of the canal, the periosteal cortex is

379 triangular in sagittal profile, with the margins defined by remodeled, obliquely oriented

380 trabeculae and an apex terminating around the mid-height of the element (Fig. 9D). The cortex is

381 slightly less vascularized than any of the intercentra with notochordal canals. It features a thin

382 deposition of lamellar bone within the vascular canals that is not appreciably different from the

383 smaller intercentra, and there is no evidence of a compact lamellar annulus. A few shallow

384 indentations on the periosteal margin may be nutrient foramina, but there are no large cavities as

385 in some of the other intercentra. A very shallow indentation on the anterior articular surface at

386 about the mid-height of the element (aside from the general concavity of the surface) may be the

387 vestiges of the notochordal canal.

388 The periosteal trabeculae gradually transition from an orderly parallel-layered matrix to

389 more irregularly spaced trabeculae separated by large erosion cavities before reaching the

390 interior endochondral trabeculae. The endochondral trabeculae are similar to the smaller

391 specimens, being thickened at the margins and thinnest at the dorsal region in sagittal profile,

392 although the intertrabecular spacing is slightly larger, particularly at the dorsal region, and the

393 trabeculae at the articular surfaces are noticeably thicker than in the smaller intercentra.

394 Secondary remodeling is more pronounced, although it still represents a small minority in

395 comparison to primary trabeculae. Secondary osteons, while also relatively rare, are noticeably

396 more abundant than in the smaller intercentra. Calcified cartilage is still abundant throughout the

397 element, and the relative abundance in this specimen to that of the smaller intercentra is not

398 appreciably different.

399

400 PEFO 38645 (Fig. 6E, 7E): This specimen is unique in possessing an unusual combination of

401 features not seen in any other specimen. The periosteal cortex is generally similar to that of other

402 large intercentra in being triangular in sagittal profile, but the apex, which is easily identified, 
403 terminates well below the mid-height of the element. Most of the cortex has been destroyed 404 except for in the margins, which include a compact lamellar annulus (Fig. 11A). This is the first 405 specimen to possess such an annulus, although there are no LAGs present (Fig. 11A). In 406 transverse profile, the cortex is mainly confined to the ventral surface (Fig. 7E). It appears that 407 the lateral and dorsolateral margins have been slightly weathered during preservation, but the 408 lateral extent of endochondral bone is still far greater than expected. However, one layer of 409 organized vascular canals in periosteal trabeculae can be identified on the dorsal margin, 410 suggesting that the cortex does extend onto this margin as noted in a presacral intercentrum 411 analyzed by Konietzko-Meier, Bodzioch, \& Sander (2013). We consider this observation more 412 tentative given the lower preservational quality of the specimen and the margins in particular. 413 Sharpey's fibers can be identified in the ventrolateral portion of the cortex.

414 In addition to being more laterally extensive than in other intercentra, the endochondral 415 trabeculae are extremely thick and densely packed at the anterior surface, both in comparison to 416 all other intercentra of this sample and in comparison to the posterior surface in which the 417 organization is more comparable to other sampled specimens. Although the trabeculae of the 418 dorsal region are thinner, as in other specimens, the absence of the lateral periosteal cortex 419 results in this network extending to the dorsolateral surface of the element. Of particular interest 420 is an unusual clustering of trabeculae in the dorsal portion of the periosteal cortex, closer to the 421 interior of the element in which a high degree of remodeling is noted. This is connected to a 422 prominent mediolateral line of thickened trabeculae that extends to the external margin. Overall, 423 secondary remodeling is observed at a higher rate than in smaller intercentra, but there is still a 424 significant amount of calcified cartilage within the interior and margins of the element. 425

426 PEFO 36874b (Fig. 6F, 7F): This specimen is more similar to the smaller PEFO $16696 \mathrm{~b}$ than to 427 PEFO 38645. The periosteal region is triangular in sagittal profile with a well-defined apex that 428 terminates below the mid-height of the element, though not to the same degree as PEFO 38645. 429 As with PEFO 16696b, the periosteal cortex maintains a constant thickness up the lateral margin. 430 Most of the parallel layers have been destroyed, and there is no evidence of a compact lamellar 431 annulus, as in PEFO 38645, nor does this appear to be a preservational artifact. The 432 vascularization of the external layers is still relatively high and the deposition of lamellar bone 
433 within the vascular canals is only slightly thicker than in PEFO 16696b. Several smaller nutrient

434 foramina are found throughout the periosteal cortex.

435 The endochondral trabecular network is essentially identical to that of PEFO $16696 \mathrm{~b}$.

436 They are thickest at the anterior and posterior surfaces, though to a significantly lesser degree

437 than PEFO 38645, and thinnest in the dorsal region of the element. Calcified cartilage is found in

438 both the interior and at the margins, but it is more sporadic in the interior than in any of the

439 smaller intercentra, and slightly more secondary remodeling can be observed.

440

441 PEFO 35392a (Fig. 6G, 7G): This element is similar to PEFO 36874a. The periosteal cortex is

442 nearly identical in shape and vascularity, but it is difficult to locate the apex in this specimen.

443 The lowest possible apex is located slightly ventral to the mid-height of the element where a

444 thickened fragment of trabeculae is located, but the precipitation of large secondary carbonates

445 that are found in the cortex but not the endochondral domains of many other large intercentra

446 continues dorsal to this. There is no evidence of an unusually thick or robust periosteal region in

447 transverse profile. There is also no evidence of a compact annulus, similar to PEFO $36874 \mathrm{~b}$ (Fig.

448 11B). The primary lamellar layers found within the vascular canals are noticeably thicker than in

449 the smallest intercentra. Two nutrient foramina are located on the dorsolateral margin of the

450 periosteal cortex. The endochondral region is also similar to the aforementioned intercentra.

451 Calcified cartilage is still present in fairly high abundance, but the degree of both cartilage and

452 secondary remodeling is markedly different than in the smallest intercentra.

453

454 PEFO 16696c (Fig. 6H, 7H): This element is similar to all of the large intercentra that lack an 455 open notochordal canal except PEFO 38645 in terms of the organization of the periosteal and 456 endochondral bone. The apex of the periosteal cortex can be more readily identified than in 457 PEFO 35392b and terminates approximately at the mid-height of the element. The cortex is still 458 relatively vascularized, though to a lesser degree than in PEFO 35392b, and there is no evidence 459 of a compact lamellar annulus (Fig. 11C). Two prominent nutrient foramina are present; these 460 are more deeply penetrating than seen in any other intercentra. Calcified cartilage occurs 461 sporadically throughout the interior and remains abundant at the margins. Secondary remodeling 462 is comparable to that of PEFO 35392b 
464 PEFO 35392b (Fig. 6I, 7I): This specimen is nearly identical to PEFO 35392b and PEFO 16696c

465 in structure and organization. The apex of the periosteal cortex terminates at the mid-height of

466 the element. The external cortex is more damaged in sagittal profile than in PEFO 35392ba

467 although the externalmost layer, consisting of a highly vascularized network, is well preserved in

468 transverse profile and is nearly identical to that of PEFO 35392a. Conversely, the interior

469 endochondral region is slightly better preserved in this specimen. There is no evidence of a

470 compact lamellar annulus, even in the transverse profile. One nutrient foramen can be identified

471 on the dorsolateral surface. The relative abundance of calcified cartilage and secondary

472 remodeling is comparable to that of the other two specimens.

473

474 PEFO 38726 (Fig. 6J, 7J): This specimen is similar to all other large intercentra regarding the

475 microanatomy; the periosteal cortex is triangular in sagittal profile, terminates slightly above the

476 mid-height of the element, and extends up the lateral margins in transverse profile. The

477 preservational condition of the element is slightly worse than in the other intercentra due to the

478 presence of fibrous bundles of secondary minerals that have damaged the interior trabecular 479 networks.

480 The external layers of the cortex are less vascularized, particularly on the lateral margins,

481 and the endochondral trabeculae are thicker at the articular surfaces in sagittal profile,

482 particularly on the anterior surface. This is somewhat comparable to the condition of PEFO

48338465 , but the degree of thickening relative to the overall length of the element is less in this

484 specimen. A compact annulus is present in which two continuous lines of a distinctly different

485 coloration to the periosteal bone that are oriented parallel to the ventral margin are visible in

486 sagittal profile (Fig. 11D). There is no evidence of any large nutrient foramina in the external

487 periosteal margin. Calcified cartilage is extremely rare in comparison to the rest of the sample

488 and is mostly found at the margins of the intercentrum, although more extensive remodeling and 489 a greater abundance of secondary osteons can be clearly noted (Fig. 12E-F).

490

491 Determination of ontogenetic stage

492 For this study, we utilized the formal Histological Ontogenetic Stages (HOS) that were created

493 for M. krasiejowensis by Konietzko-Meier, Bodzioch,\& Sander (2013). The organization of the

494 periosteal bone is used to characterize the ontogenetic stage of an individual. HOS 1 lacks any 
495 periosteal ossification, HOS 2 features a wide (thick in transverse profile) periosteal cortex, HOS

4963 features decreased vascularization in the external cortex, and HOS 4 features LAGs in the

497 external cortex, specifically within the compact annulus (Konietzko-Meier, Bodzioch, \& Sander

498 2013). Several other features also inform the relative maturity of the element, although they

499 cannot be quantified in a fashion that would permit more discrete thresholds within the different

500 HOS bins. Calcified cartilage is found in all of the samples, but it is more abundant in relatively

501 immature specimens, particularly within the interior endochondral region. This is correlated with

502 an increase in secondary remodeling of the trabeculae in this region. Additionally, the deposition

503 of layers of lamellar bone within vascular canals increases in total thickness throughout

504 ontogeny. Secondary osteons are rare throughout, but do occur more frequently in the most

505 mature specimens.

506 Based on this classification system, we do not have any specimens referable to HOS 1 in

507 the sample, as periosteal bone is clearly present in all intercentra. The majority of specimens

508 belong to HOS 2 (PEFO 36874a, PEFO 16696a, PEFO 4826, PEFO 16696b, PEFO 36874b);

509 this designation is primarily made on the basis of relatively high vascularity within the external

510 cortex. PEFO 38645 possesses a compact lamellar annulus, but no LAGs can be identified,

511 rendering it referable to HOS 3 (Fig. 11A). Several of the other large specimens (PEFO 35392a,

512 PEFO 16696c, PEFO 35392b) are referred to HOS 3 based on decreased vascularization of the

513 external cortex, as well as the various changes in relative abundances of different tissues (Fig.

514 11B-C). We note that this classification is somewhat subjective because the distinction between

515 HOS 2 and 3 (degree of vascularization of the cortex) is not absolute as in the distinction

516 between HOS 1 and 2 (presence / absence of periosteal bone) or between HOS 3 and 4 (presence

517 / absence of annulus with LAGs). These three specimens are more similar to each other than to

518 any of the smaller intercentra, and they are more immature than PEFO 38645. PEFO 16696c is

519 slightly more mature than either element of PEFO 35392 based on the degree of vascularization;

520 the relative abundance of non-quantifiable features such as calcified cartilage, secondary

521 remodeling, and lamellar deposition within the vascular canals is not appreciably different. Only

522 the largest specimen, PEFO 38726, is referable to HOS 4, as it is the only specimen with a

523 compact lamellar annulus in which LAGs can be tentatively identified (Fig. 11D). The

524 ontogenetic assignments are summarized in Table 2.

525 


\section{Discussion.}

\section{Interpretation of ontogenetic maturity}

528 The most significant finding of this study is the confirmation that, at least in the instance of the

529 sample presented in this study, the small intercentra of proportions considered typical of $A$.

530 gregorii are determined to belong to highly immature individuals. Several anatomical and

531 histological features inform the ontogenetic assignment of these specimens: (1) a perforate

532 notochordal channel, (2) a thick, more semi-circular periosteal region, (3) a greater abundance of

533 calcified cartilage, (4) a minor degree of secondary remodeling, (5) relatively thin lamellar

534 deposition within vascular canals, and (6) the absence of a compact lamellar annulus at the

535 ventral margin (Fig. 8-12). All of these features are found in the three smallest intercentra (PEFO

536 36874a, PEFO 16696a, PEFO 4826) and provide insight into the ontogenetic changes in the

537 internal structure of the axial column in metoposaurids.

538 We are confident that the open notochordal channel is a juvenile feature because its

539 closure is widespread in Triassic temnospondyls, including metoposaurids (Warren \& Snell,

540 1991). The notochordal channel is gradually reduced to a pair of perforations, one on each

541 articular surface, that migrate dorsally and eventually disappear in some taxa (Warren \& Snell,

542 1991; Danto, Witzmann \& Fröbisch, 2016). Based on comparisons to described vertebral

543 elements in M. krasiejowensis, "M." bakeri, D. ouazzoui and isolated intercentra of K. perfectus,

544 this pattern often results in an entirely smooth articular surface with no notochordal perforation

545 in mature individuals (Case, 1932; Dutuit, 1976; Warren \& Snell, 1991; Sulej, 2007).

546 Additionally, we can be certain that the notochordal channel does close in smaller individuals

547 with elongate intercentra based on PEFO 36874a, which captures the onset of cartilaginous

548 deposition into the canal and primary formation of endochondral trabeculae at the canal's

549 margins; this is further discussed below (Fig. 8C-D). The designation of the three smallest

550 intercentra as belonging to juvenile individuals is also supported by the presence of a highly

551 vascularized periosteal region, which originates near the anteroventral and posteroventral

552 margins, forming a shallower concave depression than the distinct triangle seen in larger

553 intercentra of this study and the intercentra of M. krasiejowensis (Konietzko-Meier, Bodzioch \&

554 Sander, 2013; Fig. 9). In these specimens, the apex of the periosteal region terminates well below

555 the mid-height of the element owing to the notochordal canal (Fig. 7,9). Finally, the small

556 intercentra show other evidence of a relatively immature ontogenetic stage, such as a high 
557 abundance of calcified cartilage, a high degree of vascularization in the external cortex, and 558 minimal remodeling in the interior endochondral region (Fig. 11-12). As a result, we can be 559 confident that the ossification of the notochordal channel did not occur relatively late in

560 ontogeny and conclude that all three of the small intercentra belong to an early ontogenetic stage 561 of a large metoposaurid rather than to a relatively late stage of the small A. gregorii.

Also of interest is PEFO 38645, which is characterized by a number of unusual features

563 mentioned in the description. These include: (1) extreme thickening of the endochondral

564 trabeculae at the articular surfaces, (2) the combination of a low periosteal apex with a compact

565 lamellar annulus, (3) the absence of a clear periosteal cortex on the lateral margin in transverse

566 profile, and (4) a thickened trabecular extension from the lateral margin to the inner

567 endochondral region. This element was determined to be presacral, one of the posteriormost

568 elements sampled in this study, is of an intermediate size for the sample, and is of proportions

569 typical of $K$. perfectus (Table 1). It is notably larger than any intercentrum that has been ascribed

570 to $A$. gregorii in the literature. One presacral intercentrum (UOPB 00118) of a much larger size

571 was analyzed by Konietzko-Meier, Bodzioch, \& Sander (2013), but it shows no evidence of

572 sharing any of the unusual features we have identified in PEFO 38645 other than the possible

573 extension of the periosteal cortex onto the dorsal margin of the element in transverse profile.

574 This is also true when compared to the smaller PEFO 16696a, which was more tentatively

575 identified as a presacral intercentrum. The combination of a periosteal apex that terminates well

576 below the mid-height of the element and a compact lamellar annulus is also unlike any other

577 intercentrum. Several hypotheses may explain these observations. One hypothesis is that the

578 anomalous morphology is related to the serial position of this specimen within the presacral

579 region. The marked thickening of the periosteal trabeculae on the articular surfaces and the

580 apparent thinning of the periosteal cortex on the lateral margin may be related to biomechanical

581 demands associated with intercentra in this region compared to the trunk region. The lack of

582 similarity between this specimen and the presacral intercentrum of Konietzko-Meier, Bodzioch,

$583 \&$ Sander (2013) may be related to the relatively high variability in external morphology within

584 presacral vertebrae compared to other regions of the axial skeleton that is noted in $M$.

585 krasiejowensis and D. ouazzoui (Sulej, 2007; Dutuit, 1976). Given the different mechanical

586 demands of each region, it seems probable that the developmental trajectories of different axial

587 regions were at least slightly different with regards to the onset and degree of different processes. 
588 Timing of major events within the trajectory could also be influenced by intraspecific variation

589 or developmental plasticity. Although the presence of a compact annulus suggests a more

590 advanced ontogenetic stage, most of the features identified as informative for inferring the

591 ontogenetic maturity suggest a relatively immature individual and are continuous with the

592 gradual changes noted with increasing size in this sample. These include: the absence of LAGs in

593 the annulus (found in PEFO 38726), a periosteal apex terminating well below the mid-height of

594 the element, a fairly high abundance of calcified cartilage, a low degree of remodeling, and thin

595 lamellar deposition within the vascular canals. The overall vascularity of the periosteal cortex is

596 difficult to evaluate considering that most of the tissue has either been destroyed postmortem or

597 was otherwise reduced as the biological condition. It also cannot be ruled out that the specimen

598 is in some way pathologic, although pathologies of extinct amphibians are extremely rare and

599 have only been studied with regards to an anomalous external morphology (e.g., Witzmann et al.,

600 2013). No abnormalities were apparent prior to the sampling of this specimen. Without

601 additional sampling of this axial region, it is impossible to definitively conclude or exclude any

602 of these proposed explanations. However, we do not consider this specimen to be contradictory

603 to our general conclusions regarding the ontogenetic trajectory of metoposaurid intercentra given

604 that most of the histological features are consistent with the trajectory of this sample.

605 The larger intercentra show little deviation from each other or from similarly sized and

606 positioned intercentra that were sampled by Konietzko-Meier, Bodzioch, \& Sander (2013), and

607 any deviations are consistent with the ontogenetic trajectory seen in both samples.

608 Unsurprisingly, both elements of PEFO 35392 are nearly identical in all regards, with the only

609 differences being in the quality of preservation of the different trabecular regions. All of the large

610 intercentra continue to show evidence of relative immaturity with regard to the same features as

611 the smallest elements (calcified cartilage, vascularization, lamellar deposition with the canals,

612 remodeling) up to the largest specimen, PEFO 38726 (Fig. 12). In this specimen, two continuous

613 lines found in the compact annulus are tentatively interpreted to be LAGs (Fig. 11C). A

614 significant gap in size exists between PEFO 38726 and the second largest element (PEFO

61535392 a), so it is likely that more gradual transitions were undetected in this sample. Although the

616 material is from a variety of localities and stratigraphic horizons, we have found strong evidence

617 that an increase in size of the intercentra results in progressively more advanced histological and

618 anatomical features, leading us to conclude that that the sampled material can be compiled into a 
619 generalized composite growth series as it pertains to the development of the internal structures.

620 There is no evidence for diminutive adults, as was proposed to be the condition of $A$. gregorii

621 (Hunt, 1993). However, we also note the limitations of our findings based on the isolated nature

622 of the material. Although this is typical for North American metoposaurids, the axial position of

623 each specimen could only be loosely identified, and it is highly unlikely that any two elements

624 pertain to the same individual (other than in PEFO 35392). Furthermore, even intercentra of a

625 nearly identical size, such as the three smallest specimens, may show some variation in

626 anatomical and histological features due to intraspecific variation, developmental plasticity, or

627 axial position, all of which serves to reinforce the importance of avoiding ontogenetic

628 assignments based solely on absolute size. As a result, our study is unable to draw any robust

629 conclusions regarding differences of the microanatomy and histology, either within an individual

630 or throughout ontogeny, based on the axial position. We did not sample cervical, atlas-axis, or

631 caudal intercentra, and the majority of those sampled are from the anterior to mid-trunk region.

632 Any interpretations of variation between samples of a comparable size with regard to features

633 that can only be relatively compared (e.g., abundance of calcified cartilage) would require higher

634 sample sizes and narrower constraints on the axial position than is possible from a sample of

635 completely isolated elements.

636 Finally, one feature that does not appear to be ontogenetically informative in this sample,

637 but that is nonetheless noteworthy is the open cavities found throughout the periosteal cortex in

638 many of the intercentra (Fig. 13). These cavities were only figured in the presacral intercentra of

639 M. krasiejowensis (Konietzko-Meier, Bodzioch \& Sander, 2013), but in this sample, there is no

640 apparent pattern in the distribution or relative abundance based on axial position. Because of

641 their small size and infilling with secondary minerals in many specimens, they are probably

642 impossible to consistently detect when examining the external morphology of the intercentrum.

643 The cavities likely represent nutrient foramina whose trajectories lie in more than one orthogonal

644 plane, hence why some cavities appear to terminate shallowly in the periosteal cortex while

645 others penetrate to the inner endochondral region, as well as why some of the foramina appear L-

646 shaped in sagittal profile rather than simple straight perforations. Without a high-resolution

647 three-dimensional analysis of the intercentra, it is impossible to discern if there is any pattern in

648 the trajectory, distribution, or morphology of these foramina within intercentra, across the axial

649 skeleton, or throughout ontogeny. No such patterns appear to exist in this sample. The foramina 
650 appear to remain of a constant size throughout the growth of the intercentrum, as they are

651 proportionately smaller in larger specimens.

652

653 Ontogenetic trajectory of large North American metoposaurids

654 Our findings are consistent with the hypothesis that all intercentra of this sample pertain to

655 various ontogenetic stages of a large metoposaurid. Because K. bakeri has not been identified

656 west of Texas, and its intercentra differ from those of $K$. perfectus with regard to the notochordal

657 channel (discussed below), we tentatively assign the PEFO material to K. perfectus, with the

658 understanding that future revision may be necessary as more diagnostic material is recovered

659 (Hunt, 1993; Long \& Murry, 1995). It cannot be excluded that material from the Petrified Forest

660 Member could belong to a different taxon of large metoposaurid that is presently unknown as the 661 result of a paucity of such individuals in the upper units of the Chinle Formation. It is possible

662 that the onset of ossification of the notochordal channel reflects a milestone in the development

663 of K. perfectus. In light of the hypothesis suggesting that Koskinonodon could have had

664 ecologically separated life stages (Rinehart et al., 2009) and arguments by previous workers that

665 the morphology of A. gregorii is more suited for a terrestrial lifestyle (Hunt, 1993; Spielmann \&

666 Lucas, 2012), the ossification of the notochordal canal could potentially represent the onset of a

667 fully aquatic lifestyle if small metoposaurids were semi-aquatic. This study has also produced an

668 unexpected finding that suggests some differences in timing of the ontogenetic trajectory of $K$.

669 perfectus in relation to other metoposaurids with known vertebral columns. In the original

670 description of $K$. bakeri, Case (1932) noted that the presence of a notochordal channel and its

671 persistence as reduced perforations on the articular surfaces in more mature specimens differed

672 from other metoposaurid specimens from Texas, presumably of $K$. perfectus, in that the known

673 material of the latter lacked any sort of perforation. The absence of any perforations appears in

674 the intercentra of $K$. perfectus that are described or figured in other publications (e.g., Colbert \&

675 Imbrie, 1956; Hunt, 1993; Long \& Murry, 1995; Spielmann \& Lucas, 2012), and we have also

676 found this same absence in all of the intercentra sampled here. These observations suggest that

677 with regards to timing, the ossification of the notochordal canal occurs much earlier in $K$.

678 perfectus. We note that the smallest specimen analyzed by Konietzko-Meier, Bodzioch \& Sander

679 (2013), an early juvenile (UOPB 00117), is larger than two of the three small intercentra sampled 
680 here (PEFO 16696a, PEFO 36874a) but is classified as being more ontogenetically immature

681 (HOS 1) than either specimen due to the absence of periosteal ossification (Fig. 9A-B, Table 2).

682 PEFO 36874a is of particular interest in this regard as it is clearly in the process of 683 undergoing ossification of the notochordal channel, even though it is the smallest intercentrum in 684 this sample (Fig. 8C-D). This was not evident when examining the external morphology of the 685 specimen, as the notochordal channel or pit is usually filled with secondary minerals. Precursory 686 cartilage can be clearly seen growing into the channel near the geometric center, with some 687 endochondral trabeculae forming in the wake of this deposition (Fig. 4B). The dorsal half 688 appears to be contributing more material through bone deposition, but this requires additional 689 specimens to verify (Fig. 4B). Although this specimen is the largest of the three intercentra with notochordal canals, this does not contradict our ontogenetic assignment based on an examination of the external morphology of other small, elongate intercentra at PEFO. There appears to be some variability in the exact timing of the closure of the notochordal channel, as specimens of similar size and proportion exhibit the full range of conditions, from an open channel to a smooth articular surface lacking any trace of the channel. This could be owing to a number of processes that require additional samples to evaluate, such as the progression of ossification of the vertebral column in the anterior-posterior direction or intraspecific variation in the onset of ossification. If the early stages of vertebral ossification were in some way influenced by environmental factors rather than the absolute size of the animal, developmental plasticity, which occurs in both extant and extinct amphibians, could explain how intercentra could sometimes be histologically more immature than slightly smaller ones (Newman, 1992; Schoch, 2014). As previously noted, this may also indicate a relatively fast ossification of the notochordal channel. It may be that $K$. perfectus juveniles experienced a relatively rapid burst of early endochondral ossification within the skeleton in comparison to M. krasiejowensis, such that even a slight difference in absolute size between two elements could be characterized by markedly different internal anatomy, such as the differences in notochordal canals of the four smallest specimens

706 (Fig. 8-9). As previously discussed in other sections, this could reasonably result from intraspecific variation, developmental plasticity, or axial position.

Finally, only the largest intercentrum sampled in our study (PEFO 38726) contains

709 possible LAGs in the external cortex (Fig. 11D). This element is most comparable in size to 710 UOPB 00115, which was classified as a late juvenile of HOS 3 (Konietzko-Meier, Bodzioch \& 
711 Sander, 2013) and in which no LAGs were observed. This suggests that K. perfectus may have

712 reached maturity at a smaller size than M. krasiejowensis, but again, additional sampling is

713 required. Variability in ontogenetic trajectories has been previously documented between $D$.

714 ouazzoui and M. krasiejowensis and was proposed to be the result of differing environmental

715 conditions (Konietzko-Meier \& Klein, 2013). As the Chinle depositional basin was positioned

716 closer to the equator in comparison to the environments in which D. ouazzoui and $M$.

717 krasiejowensis are found (e.g., Steiner \& Lucas, 2000; Rowe et al., 2007; Zeigler \& Geissman,

718 2011; Nordt, Atchley \& Dworkin, 2015), it is plausible that the paleoenvironment differed

719 sufficiently from that of both taxa so as to result in a distinct ontogenetic trajectory in $K$.

720 perfectus. Additional sampling of material, particularly limb elements, is needed for comparative

721 analyses to assess this possibility.

722

723 Implications for metoposaurid paleobiology

724 These findings, particularly with regard to the smallest intercentra, provide one line of evidence

725 to support a hypothesis of niche partitioning between life stages of metoposaurids, which has

726 been suggested in Koskinonodon (Rinehart et al., 2009) and in Metoposaurus (Sulej, 2007). Such

727 partitioning could reasonably have created an associated taphonomic bias, which is well

728 documented in both dense bonebeds and localities with more dispersed material. All known

729 metoposaurid bonebeds have so far produced only large, relatively mature individuals with no

730 evidence of the earliest ontogenetic stages (Case, 1932; Colbert \& Imbrie, 1956; Dutuit, 1976;

731 Hunt, 1993; Sulej, 2007; Lucas et al., 2010; Brusatte et al., 2015). Furthermore, although

732 material from mature individuals of $K$. perfectus is common in the middle Norian, material

733 referable to juveniles of the taxon is extremely rare, providing another line of support for niche

734 partitioning; to date, only two partial skulls have been described (Zanno et al., 2002; Gee and

735 Parker, in press). A juvenile specimen of "M." bakeri from Nova Scotia was first noted by Baird

736 (1986) but has only been briefly described by subsequent authors (Hunt, 1993; Sues \& Olson,

737 2015). Material of Apachesaurus gregorii is common in the Redonda Formation in New Mexico

738 but occurs mostly within a single quarry (Gregory Quarry, NMMNH locality 485) (Spielmann

739 and Lucas, 2012). As a result, the relative abundance of $A$. gregorii may not be the result of

740 ecological turnover as postulated by Hunt (1993), but may represent the preservation of

741 depositional environments inhabited by juveniles of $K$. perfectus. As bonebeds of mature 
742 metoposaurids have been interpreted as evidence of ecological aggregation prior to death, it is

743 not implausible to infer that juveniles may also have naturally aggregated separately from adults,

744 creating a preservation potential for dense assemblages of one growth stage (Lucas et al., 2010;

745 Brusatte et al., 2015). Based on the isolated and disarticulated nature of most Apachesaurus

746 material, we do not believe these deposits represent mass mortality events, but that they are more

747 likely representative of depositional environments frequented by small metoposaurids over

748 longer durations of time. This hypothesis is supported by a previous study that surveyed blue

749 paleosol localities at PEFO and found that material of many rare taxa, as well as that of $A$.

750 gregorii, are found mostly within these uncommon horizons (Loughney, Fastovsky \& Parker,

751 2011). PFV 040, PFV 215, and potentially PFV 122, the three localities from which specimens

752 for this study were sourced, are all blue paleosol horizons. This lithology is interpreted to have

753 formed in low-energy systems, primarily abandoned channels and ponds adjacent to the main

754 river channel, in contrast to the dominant red floodplain deposits in which fossil material is more

755 fragmentary and isolated (Loughney, Fastovsky \& Parker, 2011). The association of

756 Apachesaurus material with these blue paleosol localities supports the hypothesis that deposits

757 that are disproportionately skewed toward fossils of small-bodied metoposaurids (exemplified by

758 PFV 040 and PFV 215) and potentially form in different geologic settings than deposits that are

759 skewed toward large metoposaurids. This in turn supports the hypothesis of natural ecological

760 separation between life stages of metoposaurids. Additionally, taxa that are primarily associated

761 with blue paleosol horizons may not be as stratigraphically restricted as previously thought, and

762 a perceived faunal turnover may in fact be more closely linked to changes in the relative

763 likelihood of preservation of different depositional settings.

764

765 Conclusions

766 These findings reiterate the importance of evaluating the potential for morphological variation to

767 be the result of ontogeny, especially when comparing two taxa of vastly different sizes, such as

768 A. gregorii and K. perfectus. Although fossils of A. gregorii are common in late Norian deposits,

769 the vast majority of this material has consisted of isolated elongate intercentra, which we

770 demonstrate here cannot be considered apomorphic. Limited fragmentary pectoral and pelvic

771 material of $A$. gregorii has been described in the literature, but no justification for ascribing it to

772 the taxon has ever been provided (e.g., Hunt, 1993; Long \& Murry, 1995; Spielmann \& Lucas, 
773 2012). Although this material was recovered from the same quarry as cranial and vertebral

774 material, there is no published work suggesting that any of it was found in articulation with any

775 of the diagnostic cranial material (Spielmann \& Lucas, 2012). North American metoposaurid

776 specimens are frequently isolated or disarticulated, but this does not negate the importance of

777 reevaluating the taxonomic identity of this material to determine whether they preserve robust

778 diagnostic traits. It is possible that these assignments were made solely on the basis of diminutive

779 size (e.g., Hunt, 1993; Long \& Murry, 1995; Spielmann \& Lucas, 2012), which cannot be

780 utilized as in species differentiation given the role of ontogeny in producing morphological

781 variation associated with different size bins (Steyer, 2000; Horner and Goodwin, 2009;

782 Witzmann, Scholz \& Ruta, 2009). Similarly, although a large number of diagnostic cranial

783 characters have been identified for $A$. gregorii, only a single character, the shallow otic notch,

784 can be confirmed in any specimens beyond the holotype (Spielmann \& Lucas, 2012). The

785 potential for these cranial landmarks to be ontogenetically influenced has not been sufficiently

786 addressed by past workers, in spite of the widespread documentation of morphological changes

787 associated with ontogeny in both extant and extinct amphibians (Hanken, 1992; Fröbisch et al.,

788 2010; Schoch, 2014). For example, studies of other Triassic temnospondyls have shown that the

789 otic notch, occipital condyles, and cultriform process (by virtue of its relationship with the

790 interpterygoid vacuities) all play a role in bite force mechanics (Fortuny, Marcé - Nogué \&

791 Galobart, 2012; Fortuny et al., 2016; Lautenschlager, Witzmann \& Werneburg, 2016). Based on

792 these findings, the presence of shallow otic notches, reduced projection of the occipital condyles,

793 and a wider cultriform process (all supposedly diagnostic traits of A. gregorii) may in fact be

794 influenced by changing biomechanical demands throughout ontogeny, rather than being the

795 result of speciation. The potential for intraspecific variation to exert an influence on

796 metoposaurid morphology has also not been well studied in North American taxa even though

797 studies of bonebeds of M. krasiejowensis and M. algarvensis have demonstrated a higher degree

798 of variability in many cranial regions than previously thought (Sulej, 2007; Brusatte et al., 2015). 799

800 Finally, we believe that our results provide one line of evidence that $A$. gregorii is not in fact a 801 distinct species, but rather that it is an early ontogenetic stage of a large metoposaurid, such as $K$.

802 perfectus. The stratigraphic distribution that is alleged to reflect ecological turnover could 803 actually be controlled by taphonomic bias if niche partitioning characterized different life stages 
804 of $K$. perfectus. The role of ontogeny and intraspecific variation in producing morphological

805 variation in features such as cranial suture patterns, the basicranium, and the otic notch remain 806 relatively unexplored in North American metoposaurids. Discovery and study of additional

807 juvenile specimens is needed to establish a more robust ontogenetic characterization of the 808 earliest stages of metoposaurid development, but our study has also demonstrated that 809 underutilized methods of analysis such as paleohistology on existing specimens can shed new 810 light on the paleobiology of extinct taxa with implications for taxonomy and ontogeny.

811

\section{Acknowledgements}

813 Thanks to Matthew Smith (PEFO museum curator) for providing access to specimens for 814 histological analysis and to Brad Traver (PEFO superintendent) for granting permission to 815 conduct the destructive analyses. Thanks to Cathy Lash (PEFO fossil preparator) for assistance 816 with molding and casting of the specimens and to Yara Haridy (University of Toronto) for 817 instruction and assistance with the preparation and imaging of thin sections. Thanks to the 818 reviewers, Dorota Konietzko-Meier, Alexandra Houssaye, and Tomasz Sulej, and the editor, 819 Andrew Farke, for providing insightful comments that greatly improved this manuscript. Any 820 opinions, findings, or conclusions of this study represent the views of the authors and not those 821 of the U.S. Federal Government. This is Petrified Forest National Park Paleontological 822 Contribution no. 49.

823

\section{References}

825

826

827

828

829

830

831

832

833

834

- Atchley, S.C., Nordt, L.C., Dworkin, S.I., Ramezani, J., Parker, W.G., Ash, S.R., and Bowring, S.A. 2013. A linkage among Pangean tectonism, cyclic alluviation, climate change and biologic turnover in the Late Triassic: the record from the Chinle Formation, southwestern United States. Journal of Sedimentary Research 83(12): 1146-1161. DOI: $10.2110 /$ jsr.2013.89

- Baird, D. 1986. Some Upper Triassic Reptiles, Footprints, and Amphibian from New Jersey. The Mosasaur 3: 125-153.

- Branson, E.B. and Mehl, M.G. 1929. Triassic amphibians from the Rocky Mountain region. University of Missouri Studies 4: 155-239.

- Brusatte, S.L., Butler, R.J., Mateus, O. and Steyer, J.S. 2015. A new species of 
Metoposaurus from the Late Triassic of Portugal and comments on the systematics and

836 biogeography of metoposaurid temnospondyls. Journal of Vertebrate Paleontology 35(3),

837 e912988. DOI: 10.1080/02724634.2014.912988

838

- Case, E.C. 1922. New reptiles and stegocephalians from the Upper Triassic of western

839 Texas. Carnegie Institution of Washington 321: 7-84.

840

- Case, E.C. 1931. Description of a new species of Buetternia, with a discussion of the

841

842 brain case. Contributions from the Museum of Paleontology, University of Michigan

843 3(11): 187-206.

844

- Case, E.C. 1932. A collection of stegocephalians from Scurry County, Texas. Contributions from the Museum of Paleontology, University of Michigan 4: 1-56.

846

- Colbert, E.H., and Imbrie, J. 1956. Triassic metoposaurid amphibians. Bulletin of the

847 American Museum of Natural History 110(6): 399-452.

- Damiani, R. 2000. Bone histology of some Australian Triassic temnospondyl

848 amphibians: preliminary data. Modern Geology 24: 109-124.

849

- Danto, M., Witzmann, F. and Fröbisch, N.B. 2016. Vertebral development in Paleozoic

850 and Mesozoic tetrapods revealed by paleohistological data. PloS ONE 11(4): e0152586.

851 DOI: 10.1371/journal.pone.0152586

852

- de Ricqlès, A. 1975. Quelques remarques paleéohistologiques sur le problème de la 853 néoténie chez les stégocéphales. Colloques Internationaux du Centre National de la Recherche Scientifique 218: 351-363.

855

- de Ricqlès, A. 1978. Recherches paleéohistologiques sur le os long des tétrapodes VII.

856 Sur la classification, la signification fonctionnelle et l'histoire des tissus osseux des tetrapods (Deuxième partie). Annales de Paléontologie (Vértébres) 64: 153-184.

858

- de Ricqlès, A. 1979.Relations entre structures histologiques,ontogene`se, strategies démographiques et modalités évolutives: le cas des reptiles captorhinomorphes et des

860

861 stégocéphales temnospondyles. Comptes Rendus de 1'Académie des Sciences Paris 288:

862

863

864 1147-1150.

865

- de Ricqlès, A. 1981. Recherches paleéohistologiques sur le os long des teétrapodes VI. Sur les os longs des tetrapods—stégocéphales. Annales de Paléontologie (Vértébres) 67: 141-160.

- Dutuit, J.M. 1976. Introduction à l'étude paléontologique du Trias continental marocain. 
866 Description des premiers stegocephales recueillis dans le couloir d'Argana (Atlas

867 occidental). Memoires du Museum National d'Histoire Naturelle, Paris, Series C 36: 1868253.

869 - Enlow D.H. and Brown S.O. 1956. A comparative histological study of fossil and recent 870 bone tissues. Part I. General discussion. Texas Journal of Science 8: 405-443.

871 - Fortuny, J., Marcé-Nogué, J., Steyer, J.S., de Esteban-Trivigno, S., Mujal, E. and Gil, L. 872 2016. Comparative 3D analyses and palaeoecology of giant early amphibians

873 (Temnospondyli: Stereospondyli). Scientific Reports 6: 30387. DOI: 10.1038/srep30387

874 - Fortuny, J., Marcé-Nogué, J., Gil, L. and Galobart, À. 2012. Skull mechanics and the 875 evolutionary patterns of the otic notch closure in capitosaurs (Amphibia:

876 Temnospondyli). The Anatomical Record 295(7): 1134-1146. DOI: 10.1002/ar.22486

877 - Fröbisch, N.B., Olori, J.C., Schoch, R.R. and Witzmann, F. 2010. Amphibian

878 development in the fossil record. Seminars in Cell \& Developmental Biology 21(4): 424-

879 431. DOI: $10.1016 /$ j.semcdb.2009.11.001

880 - Gee, B.M. and Parker, W.G. in press. A juvenile Koskinonodon perfectus

881 (Temnospondyli: Metoposauridae) from the Late Triassic of Arizona and its implications 882 for the taxonomy of North American metoposaurids. Journal of Paleontology.

883 - Gross, W. 1934. Die Typen des mikroskopischen Knochenbaues bei fossilen

884 Stegocephalen und Reptilien. Zeitschrift für Anatomie und Entwicklungsgeschichte 203: 885 731-64.

886 - Gruntmejer, K., Konietzko-Meier, D. and Bodzioch, A. 2016. Cranial bone histology of 887 Metoposaurus krasiejowensis (Amphibia, Temnospondyli) from the Late Triassic of 888 Poland. PeerJ 4: p.e2685. DOI: 10.7717/peerj.2685

889 - Hanken, J. 1992. Life history and morphological evolution. Journal of Evolutionary $890 \quad$ Biology 5(4): 549-557.

891 - Heckert, A.B., and Lucas, S.G. 2002. Revised Upper Triassic stratigraphy of the Petrified 892 Forest National Park, Arizona, U.S.A.; pp. 1-36 in A.B. Heckert and S.G. Lucas (eds.), 893 Upper Triassic Stratigraphy and Paleontology. New Mexico Museum of Natural History 894 and Science Bulletin 21. New Mexico Museum of Natural History and Science, $895 \quad$ Albuquerque. 
896

897

898

899

900

901

902

903

904

905

906

907

908

909

910

911

912

913

914

915

916

917

918

919

920

921

922

923

924

925

926

- Horner, J.R. and Goodwin, M.B. 2009. Extreme cranial ontogeny in the Upper Cretaceous dinosaur Pachycephalosaurus. PLoS ONE 4(10): e7626. DOI: 10.1371/journal.pone.0007626

- Horner, J.R., De Ricqlès, A., and Padian, K. 1998. Long bone histology of the hadrosaurid dinosaur Maiasaura peeblesorum: growth dynamics and physiology based on an ontogenentic series of skeletal elements. Journal of Vertebrate Paleontology 20(1): 115-129.

- Hunt, A.P. 1993. A revision of the Metoposauridae (Amphibia: Temnospondyli) and description of a new genus from western North America; pp. 67-97 in M. Morales (ed.), Aspects of Mesozoic geology and paleontology of the Colorado Plateau. Museum of Northern Arizona Bulletin 59. Museum of Northern Arizona, Flagstaff.

- Hunt, A.P., and Lucas, S.G. 1993. Taxonomy and stratigraphic distribution of Late Triassic metoposaurid amphibians from Petrified Forest National Park, Arizona. Journal of the Arizona-Nevada Academy of Science 27(1): 89-96.

- Konietzko-Meier, D. and Klein, N. 2013. Unique growth pattern of Metoposaurus diagnosticus krasiejowensis (Amphibia, Temnospondyli) from the Upper Triassic of Krasiejów, Poland. Palaeogeography, Palaeoclimatology, Palaeoecology 370: 145-157. DOI: $10.1016 /$ j.palaeo.2012.12.003

- Konietzko-Meier, D. and Sander, P.M. 2013. Long bone histology of Metoposaurus diagnosticus (Temnospondyli) from the Late Triassic of Krasiejów (Poland) and its paleobiological implications. Journal of Vertebrate Paleontology 33(5):1003-1018. DOI: $10.1080 / 02724634.2013 .765886$

- Konietzko-Meier, D. and Schmitt, A. 2013. A histological study of a femur of Plagiosuchus, a Middle Triassic temnospondyl amphibian from southern Germany, using thin sections and micro-CT scanning. Netherlands Journal of Geosciences 92(2-3): 97108.

- Konietzko-Meier, D., Bodzioch, A. and Sander, P.M. 2013 (for 2012). Histological characteristics of the vertebral intercentra of Metoposaurus diagnosticus (Temnospondyli) from the Upper Triassic of Krasiejów (Upper Silesia, Poland). Earth and Environmental Science Transactions of the Royal Society of Edinburgh 103(3-4): 237-250. DOI: $10.1017 / \mathrm{S} 1755691013000273$ 
927

928

929

930

931

932

933

934

935

936

937

938

939

940

941

942

943

944

945

946

947

948

949

950

951

952

953

954

955

956

957

- Konietzko-Meier, D., Danto, M. and Gądek, K. 2014. The microstructural variability of the intercentra among temnospondyl amphibians. Biological Journal of the Linnean Society 112(4): 747-764.

- Konietzko-Meier, D., Shelton, C.D. and Sander, P.M. 2015. The discrepancy between morphological and microanatomical patterns of anamniotic stegocephalian postcrania from the Early Permian Briar Creek Bonebed (Texas). Comptes Rendus Palevol 15(1-2): 103-114. DOI: 10.1016/j.crpv.2015.06.005

- Lautenschlager, S., Witzmann, F. and Werneburg, I. 2016. Palate anatomy and morphofunctional aspects of interpterygoid vacuities in temnospondyl cranial evolution. The Science of Nature 103(9-10): 79. DOI: 10.1007/s00114-016-1402-z

- Long, R.A. and Murry, P.A. 1995. Late Triassic (Carnian and Norian) Tetrapods from the Southwestern United States. New Mexico Museum of Natural History and Science Bulletin 4. New Mexico Museum of Natural History and Science, Albuquerque.

- Loughney, K.M., Fastovsky, D.E. and Parker, W.G. 2011. Vertebrate fossil preservation in blue paleosols from the Petrified Forest National Park, Arizona, with implications for vertebrate biostratigraphy in the Chinle Formation. Palaios, 26(11): 700-719. DOI: 10.2110/palo.2011.p11-017r

- $\quad$ Lucas, S.G., Rinehart, L.F., Krainer, K., Spielmann, J.A. and Heckert, A.B. 2010. Taphonomy of the Lamy amphibian quarry: a Late Triassic bonebed in New Mexico, USA. Palaeogeography, Palaeoclimatology, Palaeoecology 298(3): 388-398. DOI: 10.1016/j.palaeo.2010.10.025

- Martz, J.W. and Parker, W.G. 2010. Revised lithostratigraphy of the Sonsela Member (Chinle Formation, Upper Triassic) in the Southern Part of Petrified Forest National Park, Arizona. PLoS ONE 5(2): e9329. DOI: 10.1371/journal.pone.0009329

- McHugh, J.B. Paleohistology and histovariability of the Permian stereospondyl Rhinesuchus. Journal of Vertebrate Paleontology 34(1): 59-68. DOI: $10.1080 / 02724634.2013 .787429$

- McHugh, J.B. Paleohistology of Micropholis stowi (Dissorophoidea) and Lydekkerina huxleyi (Lydekkerinidae) humeri from the Karoo Basin of South Africa, and implications for bone microstructure evolution in temnospondyl amphibians. Journal of Vertebrate Paleontology 35(1): p. e902845. DOI: 10.1080/202724634.2014.902845 
958

959

960

961

962

963

964

965

966

967

968

969

970

971

972

973

974

975

976

977

978

979

980

981

982

983

984

985

986

- Mueller, B.D. 2007. Koskinonodon Branson and Mehl, 1929, a replacement name for the preoccupied temnospondyl Buettneria Case, 1922. Journal of Vertebrate Paleontology 27(1): 225-225. DOI: 10.1671/0272-4634(2007)27[225:KBAMAR]2.0.CO;2

- Mukherjee, D., Ray, S. and Sengupta, D.P. 2010. Preliminary observations on the bone microstructure, growth patterns, and life habits of some Triassic temnospondyls from India. Journal of Vertebrate Paleontology 30(1): 78-93. DOI:

$10.1080 / 02724630903409121$

- National Park Service. 2007. National Park Service Museum Handbook: Part III. Washington D.C.: Bacharach, J., Cumberland, D., Gray, J., Jones, B., Kilby, V., Valentine, J., Vogt-O’Connor, D., Weber, S. 554 pp.

- Newman, R.A. 1992. Adaptive plasticity in amphibian metamorphosis. BioScience 42(9): 671-678.

- Nordt, L., Atchley, S. and Dworkin, S. 2015. Collapse of the Late Triassic megamonsoon in western equatorial Pangea, present-day American Southwest. Geological Society of America Bulletin 127(11-12): 1798-1815. DOI: 10.1130/B31186.1

- Padian, K. 2013. Why study the bone microstructure of fossil tetrapods?, pp. 1-12 in K. Padian and E.-T. Lamm (eds.), Bone Histology of Fossil Tetrapods. University of California Press, Berkeley.

- Parker, W.G. and Martz, J.W. 2011. The Late Triassic (Norian) Adamanian-Revueltian tetrapod faunal transition in the Chinle Formation of Petrified Forest National Park, Arizona. Earth and Environmental Science Transactions of the Royal Society of Edinburgh 101(3-4): 231-260. DOI: 10.1017/S1755691011020020

- $\quad$ Ray, S., Mukherjee, D. and Bandyopadhyay, S. 2009. Growth patterns of fossil vertebrates as deduced from bone microstructure: case studies from India. Journal of Biosciences 34(5): 661-672. DOI: 10.1007/s12038-009-0055-X

- Rinehart, L.F. and Lucas, S.G. 2009. Limb allometry and lateral line groove development indicates terrestrial-to-aquatic lifestyle transition in Metoposauridae (Amphibia: Temnospondyli) [paper no. 96-14]. Geological Society of America Abstracts with Program 41(7): 263. 
987

988

989

990

991

992

993

994

995

996

997

998

999

1000

1001

1002

1003

1004

1005

1006

1007

1008

1009

1010

1011

1012

1013

1014

1015

1016

1017

- $\quad$ Rowe, C.M., Loope, D.B., Oglesby, R.J., Van der Voo, R. and Broadwater, C.E. 2007. Inconsistencies between Pangean reconstructions and basic climate controls. Science 318(5854): 1284-1286. DOI: 10.1126/science.1146639

- Sanchez, S. and Schoch, R.R. 2013. Bone histology reveals a high environmental and metabolic plasticity as a successful evolutionary strategy in a long-lived homeostatic Triassic temnospondyl. Evolutionary Biology 40(4): 627-647. DOI 10.1007/s11692-013$9238-3$

- Sanchez, S., de Ricqlès, A., Schoch, R. and Steyer, J.S. 2010a. Developmental plasticity of limb bone microstructural organization in Apateon: histological evidence of paedomorphic conditions in branchiosaurs. Evolution \& Development 12(3): 315-328. DOI: $10.1111 / \mathrm{j} .1525-142 X .2010 .00417 . \mathrm{x}$

- Sanchez, S., Germain, D., De Ricqlès, A., Abourachid, A., Goussard, F. and Tafforeau, P. 2010b. Limb-bone histology of temnospondyls: implications for understanding the diversification of palaeoecologies and patterns of locomotion of Permo-Triassic tetrapods. Journal of Evolutionary Biology 23(10): 2076-2090. DOI: 10.1111/j.14209101.2010.02081.x

- Schoch, R.R. 2014. Life cycles, plasticity and palaeoecology in temnospondyl amphibians. Palaeontology, 57(3): 517-529. DOI: 10.1111/pala.12100

- Spielmann, J.A. and Lucas, S.G. 2012. Tetrapod Fauna of the Upper Triassic Redonda Formation East-central New Mexico: The Characteristic Assemblage of the Apachean Land-vertebrate Faunachron. New Mexico Museum of Natural History and Science Bulletin 55. New Mexico Museum of Natural History and Science, Albuquerque.

- Steiner, M.B. and Lucas, S.G. 2000. Paleomagnetism of the Late Triassic Petrified Forest Formation, Chinle Group, western United States: Further evidence of "large" rotation of the Colorado Plateau. Journal of Geophysical Research 105(B11): 25-791.

- Steyer, J.S. 2000. Ontogeny and phylogeny in temnospondyls: a new method of analysis. Zoological Journal of the Linnean Society 130(3): 449-467. DOI: $10.1111 / \mathrm{j} .1096-3642.2000 . t b 01637 . \mathrm{x}$

- Steyer, J.S., Laurin, M., Castanet, J. and De Ricqlès, A. 2004. First histological and skeletochronological data on temnospondyl growth: palaeoecological and palaeoclimatological implications. Palaeogeography, Palaeoclimatology, 
1018

1019

1020

1021

1022

1023

1024

1025

1026

1027

1028

1029

1030

1031

1032

1033

1034

1035

1036

1037

1038

1039

1040

1041

1042

1043

1044

1045

1046

1047

1048

Palaeoecology 206(3): 193-201. DOI: 10.1016/j.palaeo.2004.01.003

- Sues, H.D. and Olsen, P.E., 2015. Stratigraphic and temporal context and faunal diversity of Permian-Jurassic continental tetrapod assemblages from the Fundy rift basin, eastern Canada. Atlantic Geology 51(1): 139-205. DOI: 10.4138/atlgeol.2015.006

- Sulej, T. 2007. Osteology, variability, and evolution of Metoposaurus, a temnospondyl from the Late Triassic of Poland. Palaeontologia Polonica 64: 29-139.

- Warren, A. and Snell, N. 1991. The postcranial skeleton of Mesozoic temnospondyl amphibians: a review. Alcheringa 15(1): 43-64.

- Warren, A. and Davey, L. 1992. Folded teeth in temnospondyls - a preliminary study. Alcheringa 16(2): 107-132. DOI: 10.1080/03115519028619036

- Warren, A. and Turner, S. 2005. Tooth histology patterns in early tetrapods and the presence of 'dark dentine.' Earth and Environmental Science Transactions of the Royal Society of Edinburgh 96(2): 113-130. DOI: 10.1017/S0263593300001267

- Werning, S. 2012. The ontogenetic osteohistology of Tenontosaurus tilletti. PLoS ONE 7(3): e33539. DOI: 10.1371/journal.pone.0033539

- Witzmann, F. 2009. Comparative histology of sculptured dermal bones in basal tetrapods, and the implications for the soft tissue dermis. Palaeodiversity 2: 233-270.

- Witzmann, F. and Soler-Gijón, R. 2010. The bone histology of osteoderms in temnospondyl amphibians and in the chroniosuchian Bystrowiella. Acta Zoologica 91(1): 96-114. DOI: 10.1111/j.1096-3642.2009.00599.x

- Witzmann, F., Rothschild, B.M., Hampe, O., Sobral, G., Gubin, Y.M. and Asbach, P. 2013. Congenital Malformations of the Vertebral Column in Ancient Amphibians. Anatomia, Histologia, Embryologia 43(2):90-102.

- Witzmann, F., Scholz, H. and Ruta, M. 2009. Morphospace occupation of temnospondyl growth series: a geometric morphometric approach. Alcheringa, 33(3): 237-255. DOI: 10.1080/03115510903043606

- Zanno, L. E., Heckert, A. B., Krzyzanowski, S. E., and Lucas, S. G. 2002. Diminutive metoposaurid skulls from the Upper Triassic Blue Hills (Adamanian: latest Carnian) of Arizona; pp. 121-126 in A.B. Heckert and S.G. Lucas (eds.), Upper Triassic Stratigraphy and Paleontology. New Mexico Museum of Natural History and Science Bulletin 21. New Mexico Museum of Natural History and Science, Albuquerque. 
1049

1050

1051

1052

1053 Figure Captions

1054 Figure 1. Map of PEFO showing localities of sampled specimens. Localities and associated 1055

1056

1057

1058

1059

1060

1061

1062

1063

1064

1065

1066

1067

1068

1069

1070

1071

1072

1073

1074

1075

1076

1077

1078

1079
- Zeigler, K.E. and Geissman, J.W. 2011. Magnetostratigraphy of the Upper Triassic Upper Triassic sequences. Geosphere 7(3): 802-829. DOI: 10.1130/GES00628.1 Chinle Group of New Mexico: Implications for regional and global correlations among specimens are as follows: PFV 122 (Blue Mesa Member): PEFO 4826 and PEFO 38726; PFV 040 (Petrified Forest Member): PEFO 38645; PFV 215 (Petrified Forest Member): PEFO 36874, PEFO 16696, and PEFO 35392.

Figure 2. Stratigraphic column of PEFO showing position of sampled specimens and localities. Localities and associated specimens are as follows: PFV 122 (Blue Mesa Member): PEFO 4826 and PEFO 38726; PFV 040 (Petrified Forest Member): PEFO 38645; PFV 215 (Petrified Forest Member): PEFO 36874, PEFO 16696, and PEFO 35392.

Figure 3. Photographs of sampled specimens in anterior and lateral profiles. (A) PEFO 38726; (B) PEFO 4826; (C) PEFO 38645; (D-E) PEFO 36874; (F-G) PEFO 35392; (H-J) PEFO 16696. Order of photographed specimens mirrors their listed order in Table 1. Scale bar equal to $2 \mathrm{~cm}$.

Figure 4. Measurement positions and sectioning planes of the intercentra. (A) measurement positions for length, width, and height of intercentrum (PEFO 38726); (B) sagittal plane of sectioning; (C) transverse plane of sectioning. Scale bar equal to $2 \mathrm{~cm}$.

Figure 5. Microanatomy of sectioned intercentra. (A) a typical small intercentrum, PEFO 16696a, in sagittal profile; (B) the same specimen in transverse profile; (C) a typical large intercentrum, PEFO 16696c in sagittal profile; (D) the same specimen in transverse profile. Abbreviations: $\mathrm{en}=$ endochondral bone; $\mathrm{nc}=$ notochordal canal; $\mathrm{p}=$ periosteal bone. Scale bars equal to $4 \mathrm{~mm}$.

Figure 6. Microphotographs of the sagittal sections of sampled specimens. (A) PEFO 36874a; (B) PEFO 16696a; (C) PEFO 4826; (D) PEFO 16696b; (E) PEFO 38645; (F) PEFO 36874b (G) PEFO 35392a; (H) PEFO 16696c; (I) PEFO 35392; (J) PEFO 38726. Scale bars equal to $4 \mathrm{~mm}$.

Figure 7. Microphotographs of the transverse sections of sampled specimens. (A) PEFO 36874a; (B) PEFO 16696a; (C) PEFO 4826; (D) PEFO 16696b; (E) PEFO 38645; (F) PEFO 
1080

1081

1082

1083

1084

1085

1086

1087

1088

1089

1090

1091

1092

1093

1094

1095

1096

1097

1098

1099

1100

1101

1102

1103

1104

1105

1106

1107

1108

36874b (G) PEFO 35392a; (H) PEFO 16696c; (I) PEFO 35392; (J) PEFO 38726. Note that because all specimens were first sectioned in the sagittal plane, all transverse sections are only half-sections. Scale bars equal to $4 \mathrm{~mm}$.

Figure 8. Microphotographs of the notochordal channel in three small specimens in sagittal profile. (A) PEFO 4826; (B) PEFO16696a; (C) PEFO 36874a; (D) close-up of the closure of the notochordal canal in polarized light. Abbreviations: $\mathrm{en}=$ endochondral bone; $\mathrm{nc}=$ notochordal canal; $\mathrm{p}=$ periosteal bone. Scale bars equal to $1 \mathrm{~mm}$.

Figure 9. Microphotographs of the periosteal cortex in four small specimens in sagittal profile. (A) PEFO 36874a; (B) PEFO 16696a; (C) PEFO 4826; (D) PEFO 16696b. Scale bars equal to $1 \mathrm{~mm}$.

Figure 10. Microphotographs of the dorsal endochondral region in three small specimens in sagittal profile. (A) PEFO 36874a; (B) PEFO 16696a; (C) PEFO 4826. Scale bars equal to 1 $\mathrm{mm}$.

Figure 11. Microphotographs of the external cortex in large intercentra. (A) PEFO 38645 in sagittal profile; (B) the same specimen in transverse profile; (C) PEFO 35392a; (D) the same specimen in transverse profile; (E) PEFO 16696c; (F) the same specimen in transverse profile; (G) PEFO 38726; $(\mathrm{H})$ the same specimen in transverse profile. Arrows indicate the position of the LAGs in PEFO 38726. Abbreviation: a = annulus. Scale bars equal to $1 \mathrm{~mm}$.

Figure 12. Microphotographs of calcified cartilage and secondary remodeling in transverse

profile. (A) PEFO 36874a in the interior endochondral region; (B) calcified cartilage in the same specimen in polarized light; (C) PEFO 35392b in the inner endochondral region; (D) calcified cartilage in the same specimen in polarized light; (E) PEFO 38726 in the interior endochondral region; (F) absence of calcified cartilage and abundant secondary remodeling in the same specimen in polarized light. Scale bars equal to $100 \mu \mathrm{m}$.

Figure 13. Microphotographs of nutrient foramina in transverse profile. (A) nutrient foramen from the ventral periosteal surface PEFO 4826; (B) same specimen in polarized light; (C) nutrient foramen from the lateral surface of PEFO 16696c; (D) same specimen in polarized light; (E) nutrient foramen from the dorsolateral surface of PEFO 36874a; (F) same specimen in polarized light. Scale bars equal to $500 \mu \mathrm{m}$. 


\section{Figure 1}

Map of PEFO showing localities of sampled specimens.

Localities and associated specimens are as follows: PFV 122 (Blue Mesa Member): PEFO 4826 and PEFO 38726; PFV 040 (Petrified Forest Member): PEFO 38645; PFV 215 (Petrified Forest Member): PEFO 36874, PEFO 16696, and PEFO 35392. 


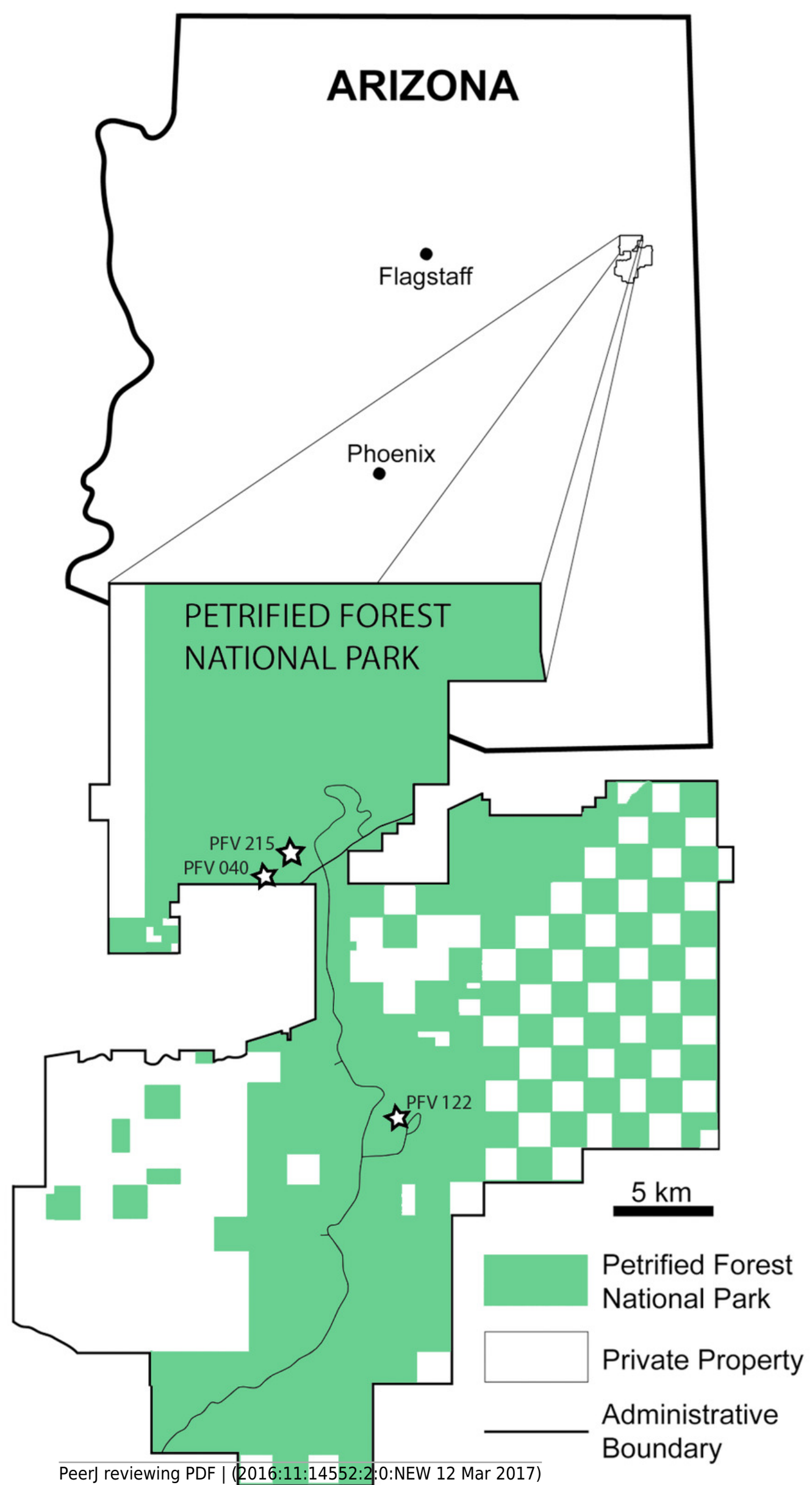




\section{Figure 2}

Stratigraphic column of PEFO showing position of sampled specimens and localities.

Localities and associated specimens are as follows: PFV 122 (Blue Mesa Member): PEFO 4826 and PEFO 38726; PFV 040 (Petrified Forest Member): PEFO 38645; PFV 215 (Petrified Forest Member): PEFO 36874, PEFO 16696, and PEFO 35392. 


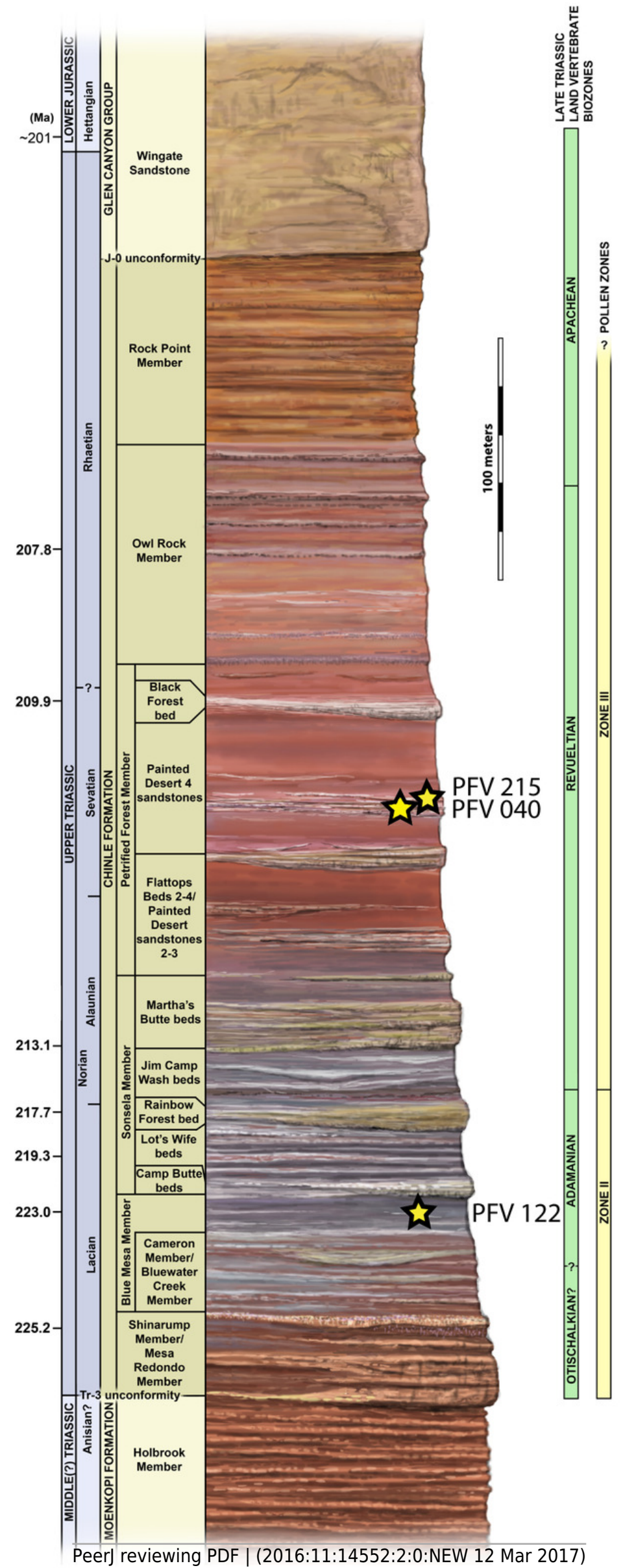




\section{Figure 3}

Photographs of sampled specimens in anterior and lateral profiles.

(A) PEFO 38726; (B) PEFO 4826; (C) PEFO 38645; (D-E) PEFO 36874; (F-G) PEFO 35392; (H-J)

PEFO 16696. Order of photographed specimens mirrors their listed order in Table 1. Scale bar equal to $2 \mathrm{~cm}$. 
(A)
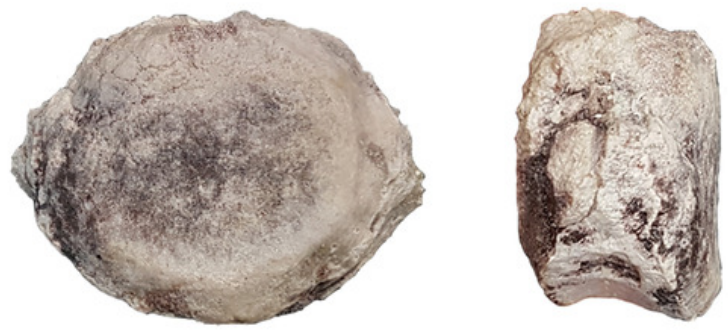

(B)
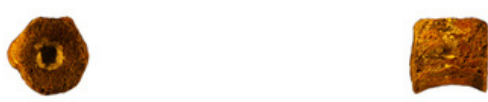

(C)
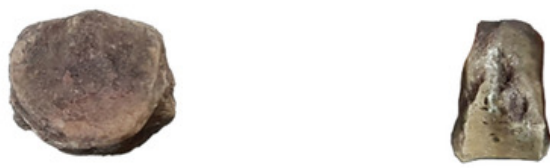

(D)

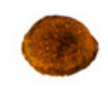

6.1

(E)
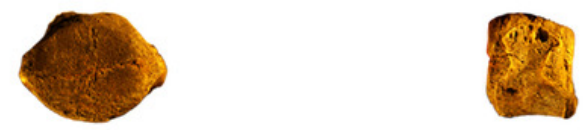

(F)
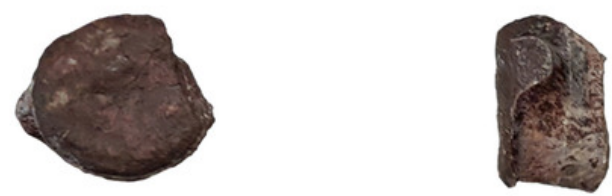

(G)
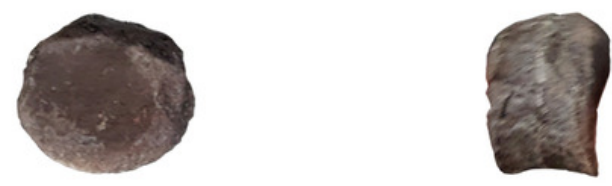

(H)
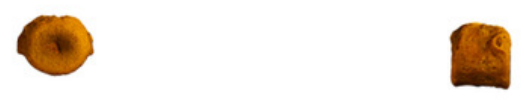

(I)
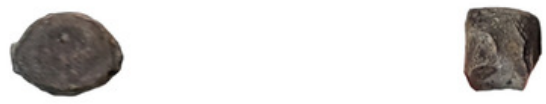

(J)
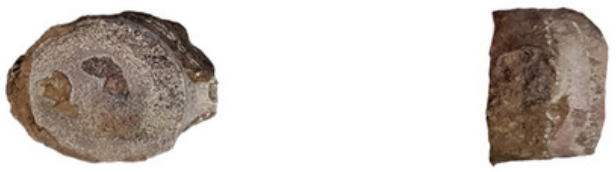

$2 \mathrm{~cm}$ 
Figure 4

Measurement positions and sectioning planes of the intercentra.

(A) measurement positions for length, width, and height of intercentrum (PEFO 38726); (B) sagittal plane of sectioning; (C) transverse plane of sectioning. Scale bar equal to $2 \mathrm{~cm}$.

(A)

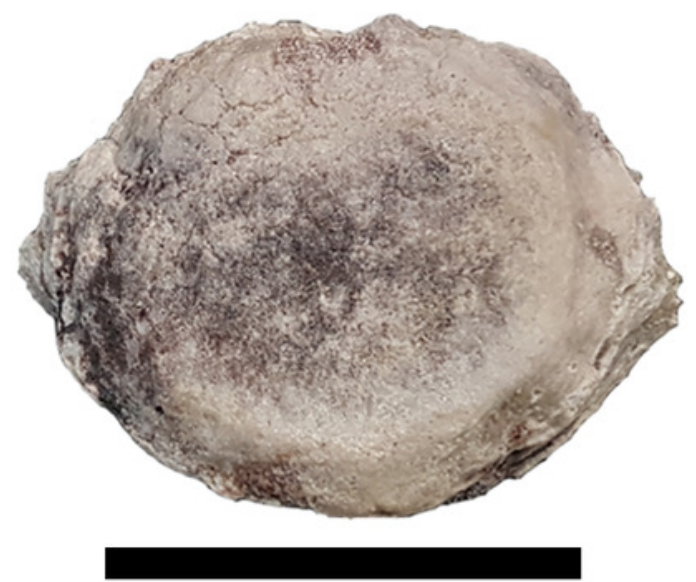

width

(B)

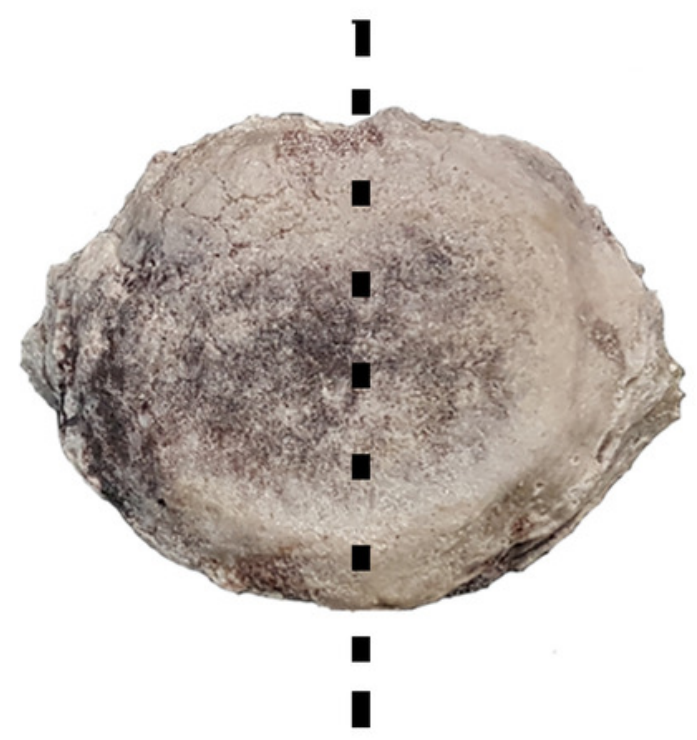

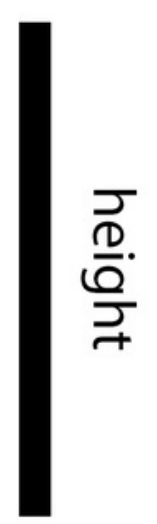

(C)

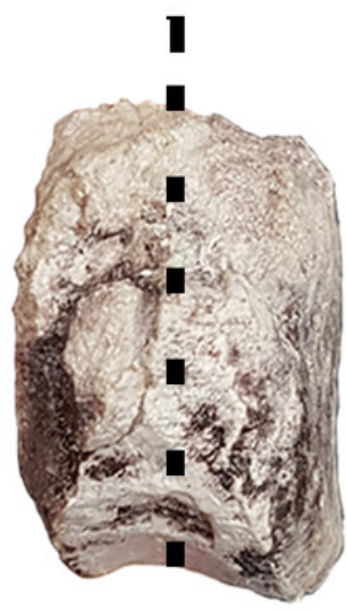

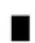




\section{Figure 5}

Microanatomy of sectioned intercentra.

(A) a typical small intercentrum, PEFO 16696a, in sagittal profile; (B) the same specimen in transverse profile; (C) a typical large intercentrum, PEFO 16696c in sagittal profile; (D) the same specimen in transverse profile. Abbreviations: en = endochondral bone; $\mathrm{nc}=$ notochordal canal; $p=$ periosteal bone. Scale bars equal to $4 \mathrm{~mm}$. 


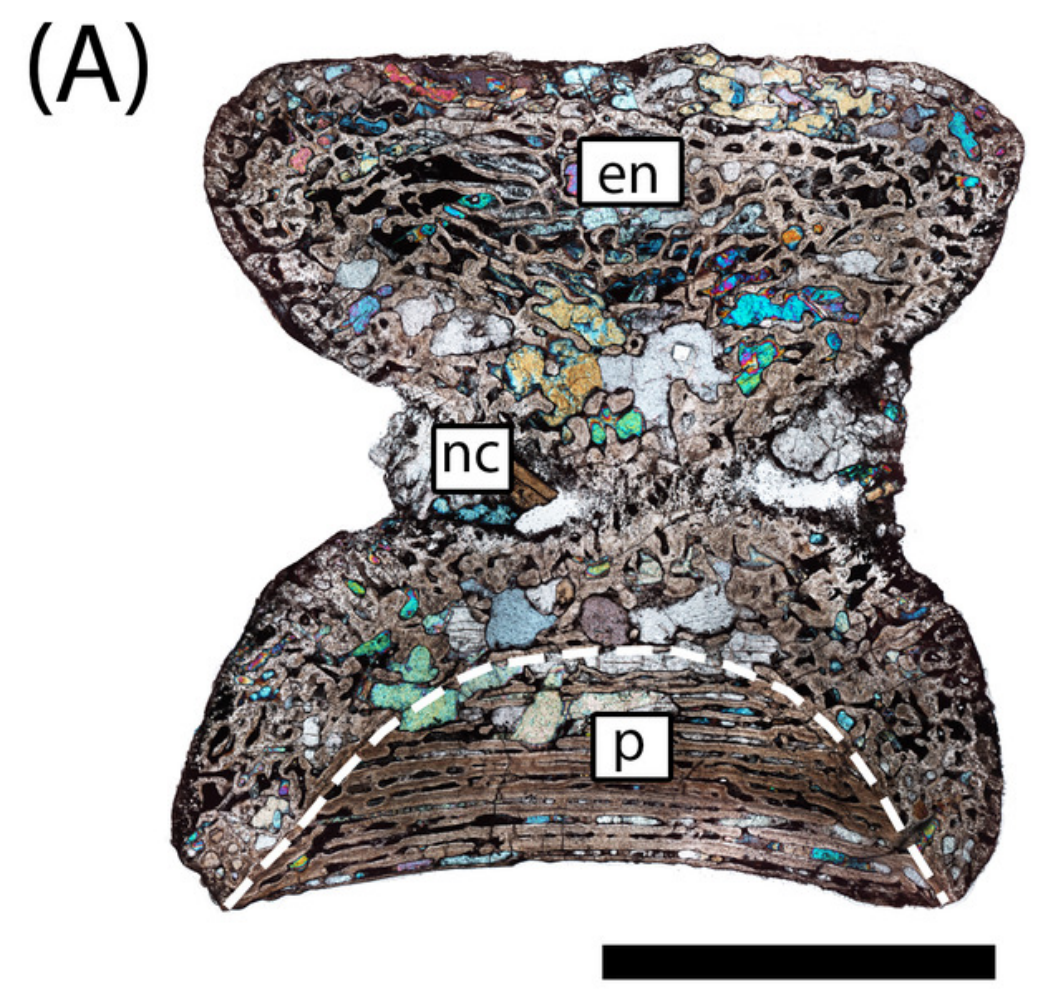

(B)

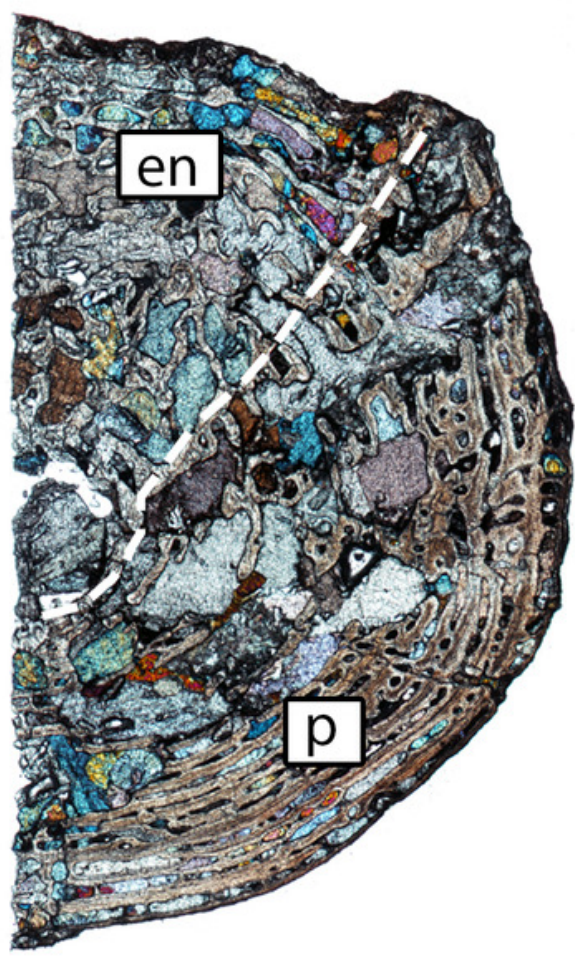

(C)

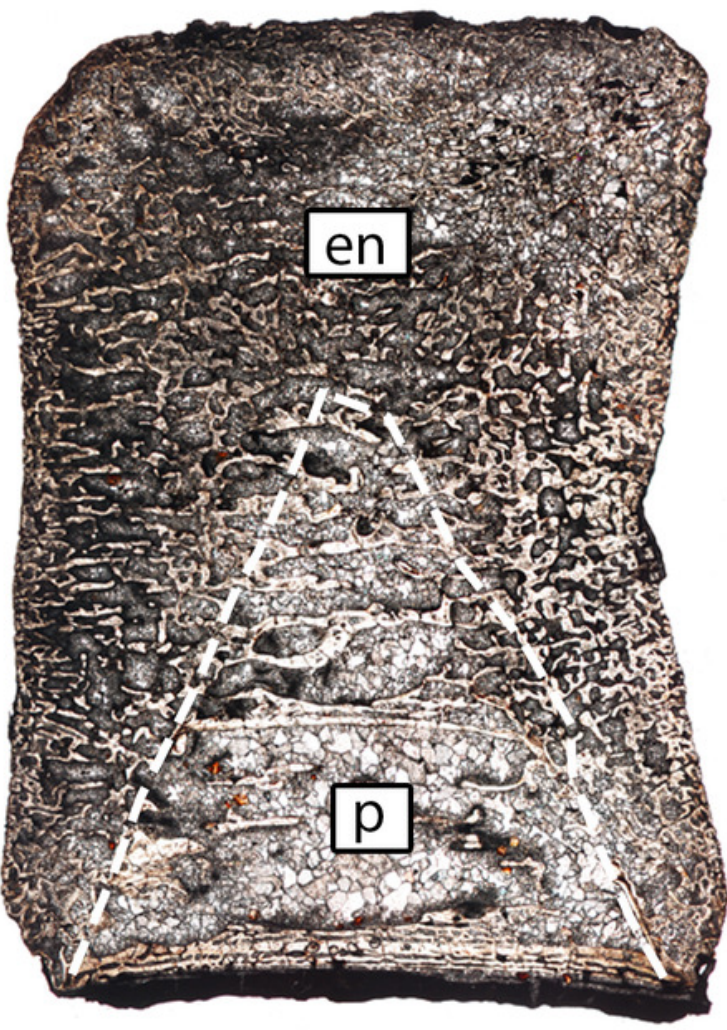

(D)

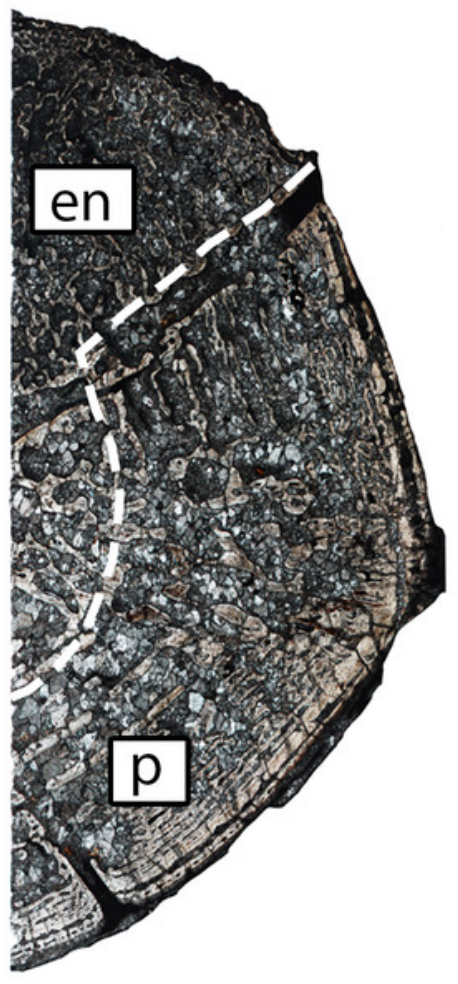


Figure 6

Microphotographs of the sagittal sections of sampled specimens.

(A) PEFO 36874a; (B) PEFO 16696a; (C) PEFO 4826; (D) PEFO 16696b; (E) PEFO 38645; (F)

PEFO 36874b (G) PEFO 35392a; (H) PEFO 16696c; (I) PEFO 35392; (J) PEFO 38726. Scale bars equal to $4 \mathrm{~mm}$. 
(A)

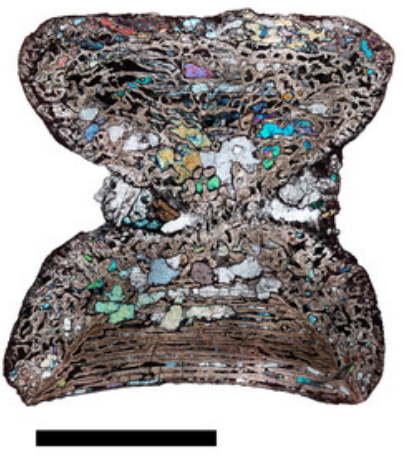

(D)

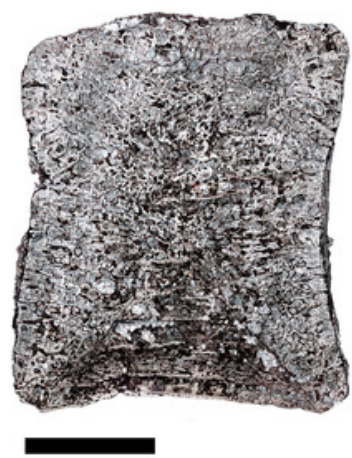

(G)

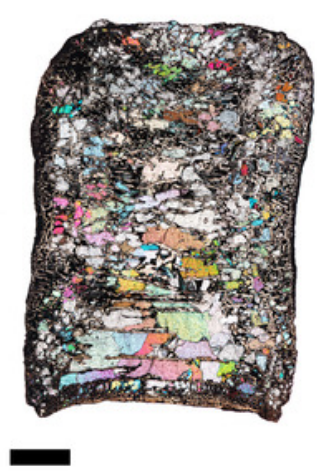

(J)

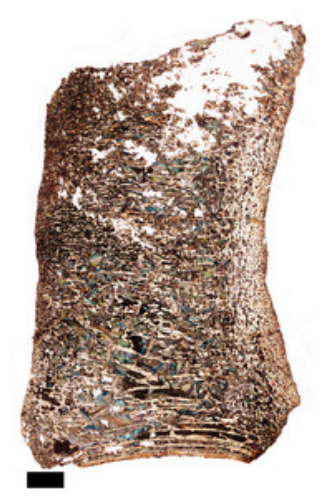

(B)

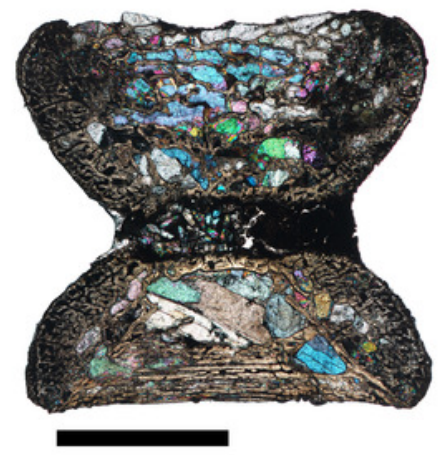

(E)

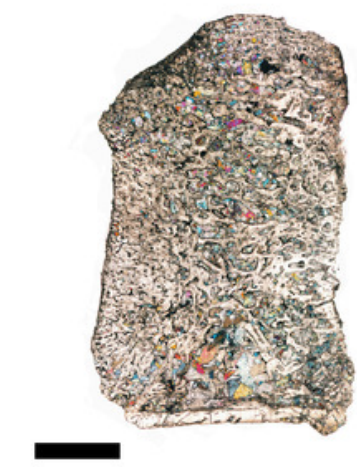

$(\mathrm{H})$

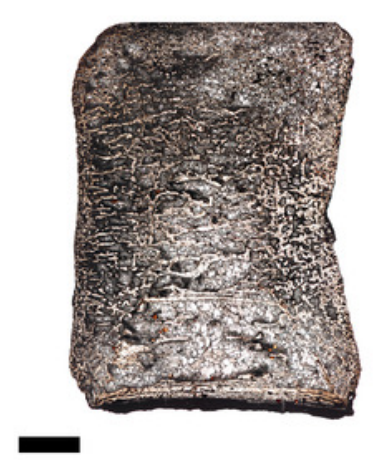

(C)

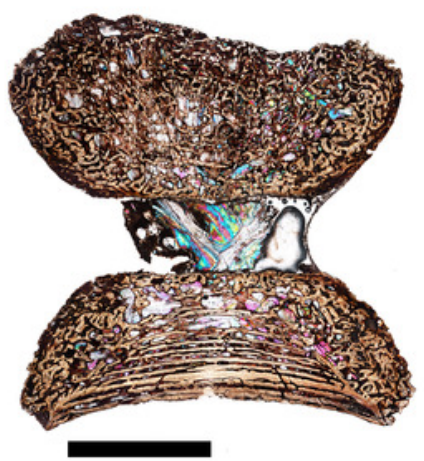

(F)

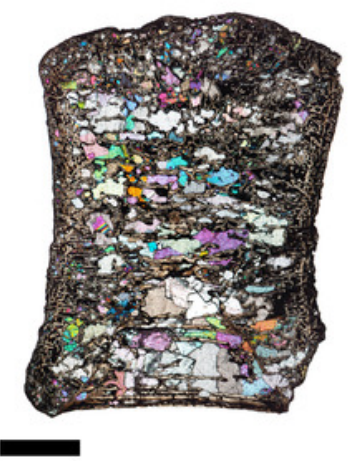

(l)

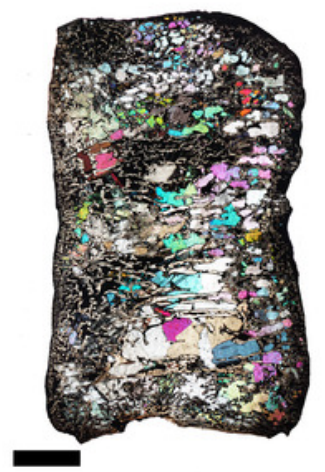




\section{Figure 7}

Microphotographs of the transverse sections of sampled specimens.

(A) PEFO 36874a; (B) PEFO 16696a; (C) PEFO 4826; (D) PEFO 16696b; (E) PEFO 38645; (F) PEFO 36874b (G) PEFO 35392a; (H) PEFO 16696c; (I) PEFO 35392; (J) PEFO 38726. Note that because all specimens were first sectioned in the sagittal plane, all transverse sections are only half-sections. Scale bars equal to $4 \mathrm{~mm}$. 
(A)

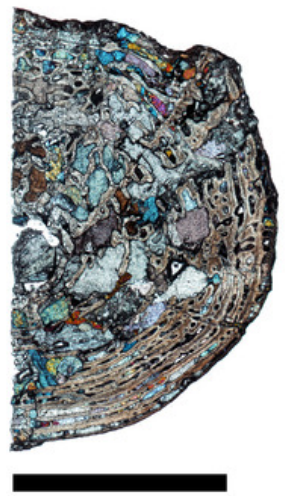

(D)

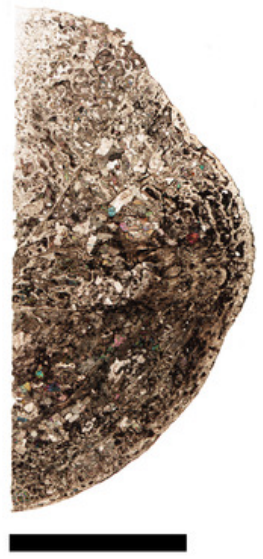

(G)

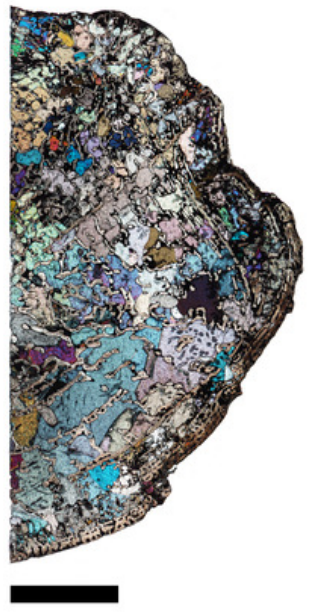

(J)

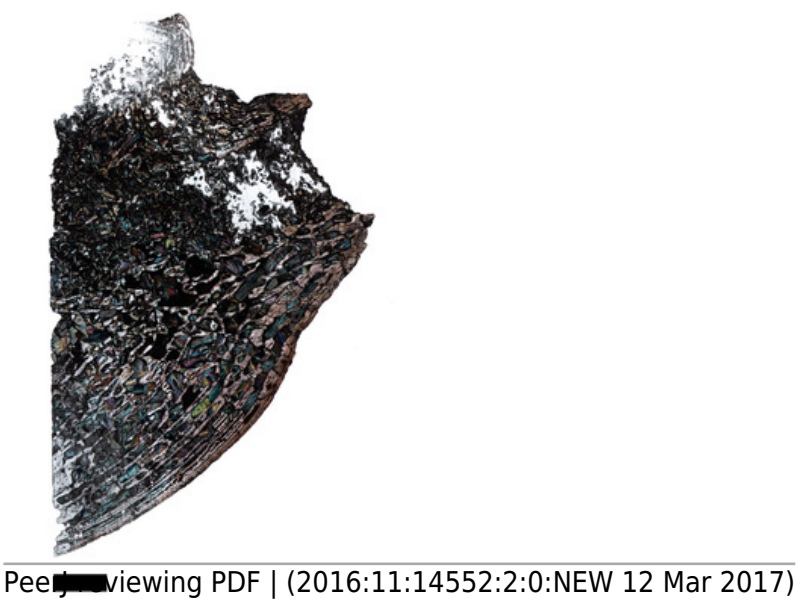

(B)

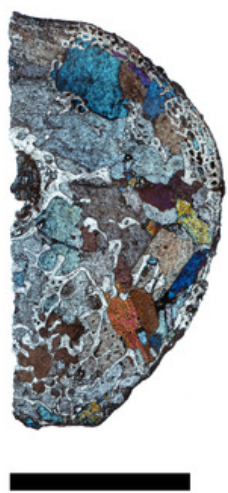

(E)

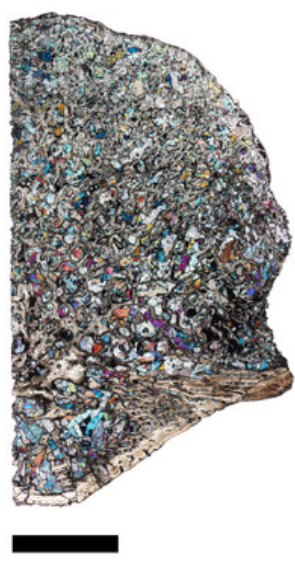

(H)

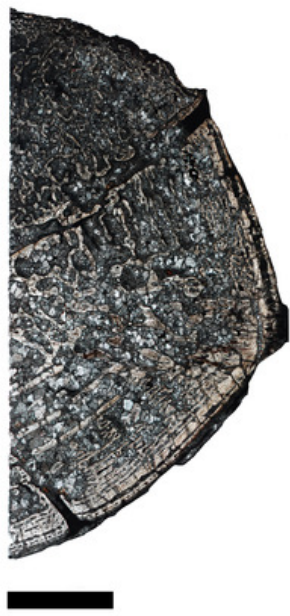

(C)

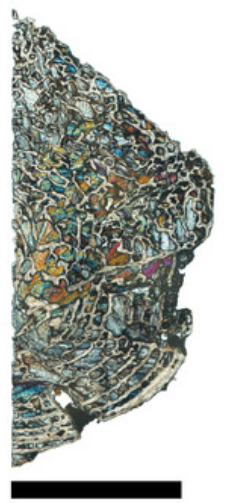

(F)

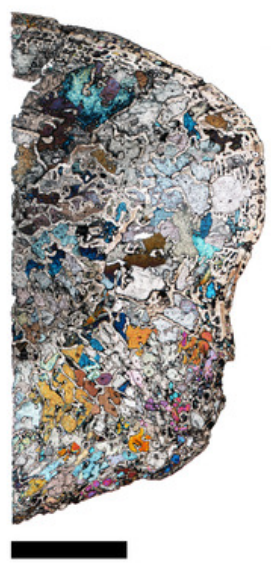

(I)

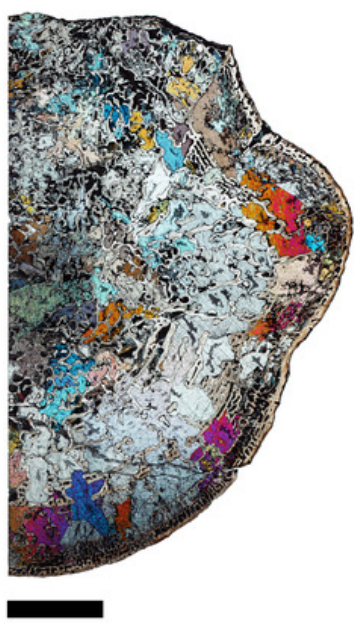




\section{Figure 8}

Microphotographs of the notochordal channel in three small specimens in sagittal profile.

(A) PEFO 4826; (B) PEFO16696a; (C) PEFO 36874a; (D) close-up of the closure of the notochordal canal in polarized light. Abbreviations: en = endochondral bone; $\mathrm{nc}=$ notochordal canal; $p=$ periosteal bone. Scale bars equal to $1 \mathrm{~mm}$.

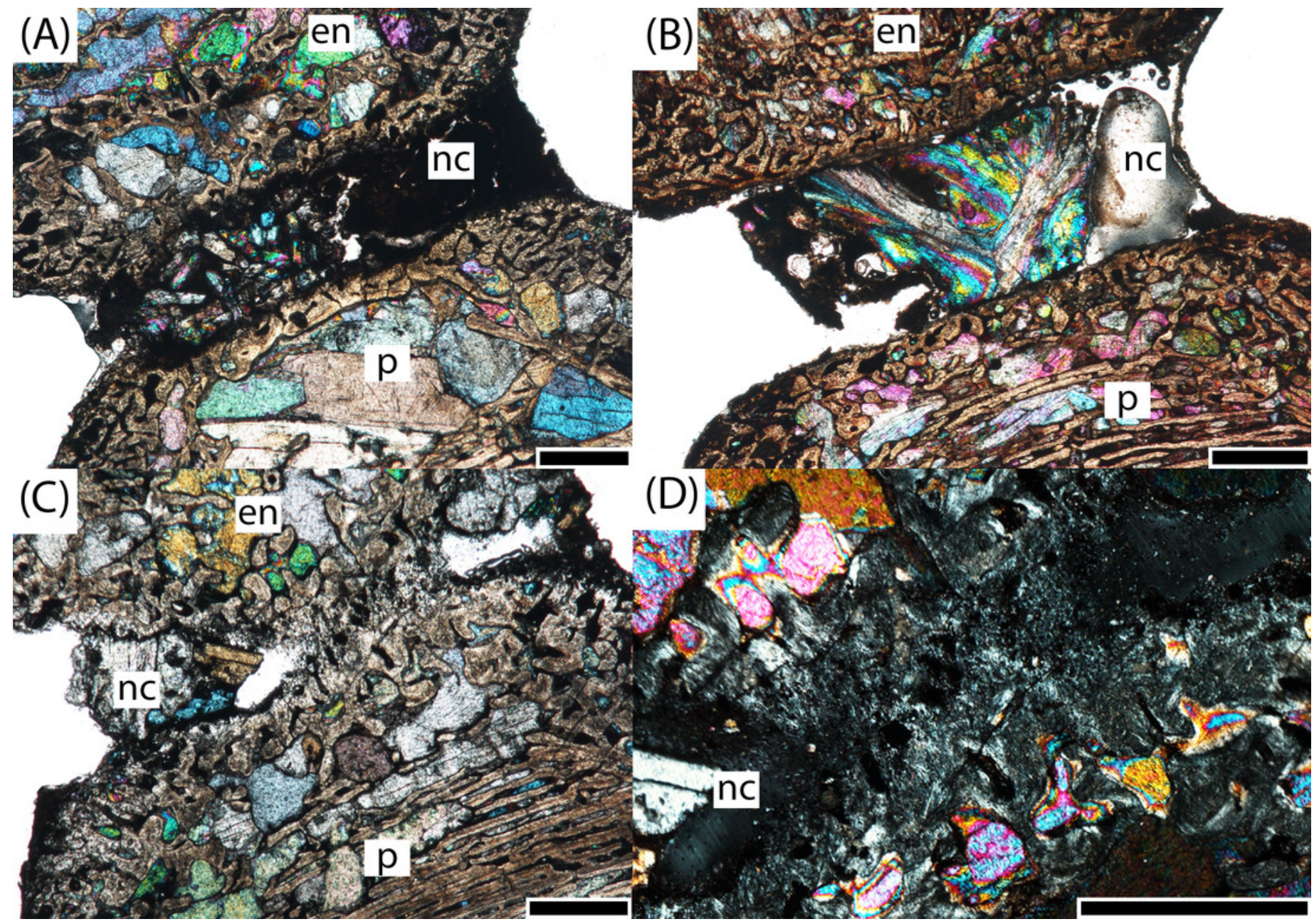


Figure 9

Microphotographs of the periosteal cortex in four small specimens in sagittal profile.

(A) PEFO 36874a; (B) PEFO 16696a; (C) PEFO 4826; (D) PEFO 16696b. Scale bars equal to 1 $\mathrm{mm}$.

(A)

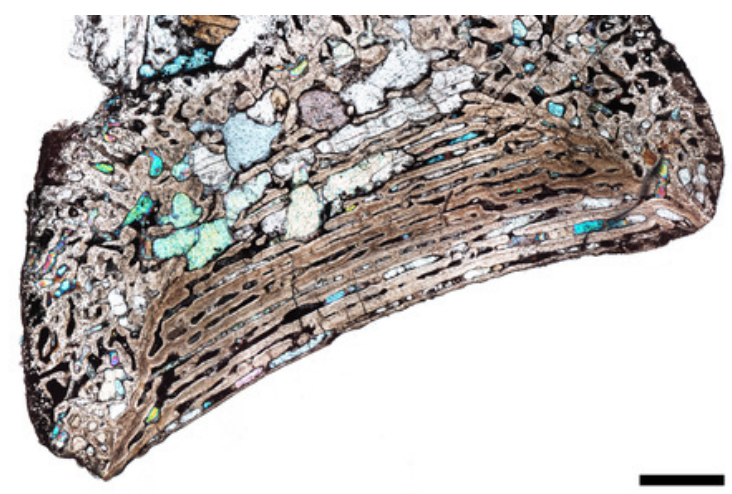

(B)

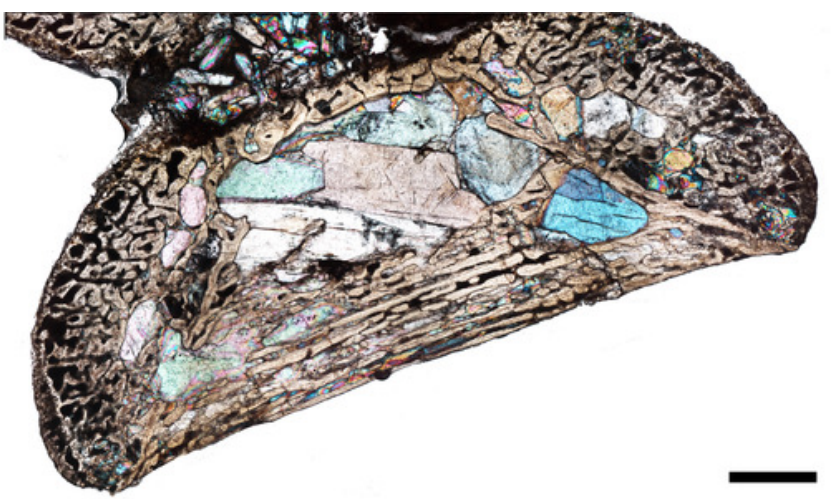

(C)

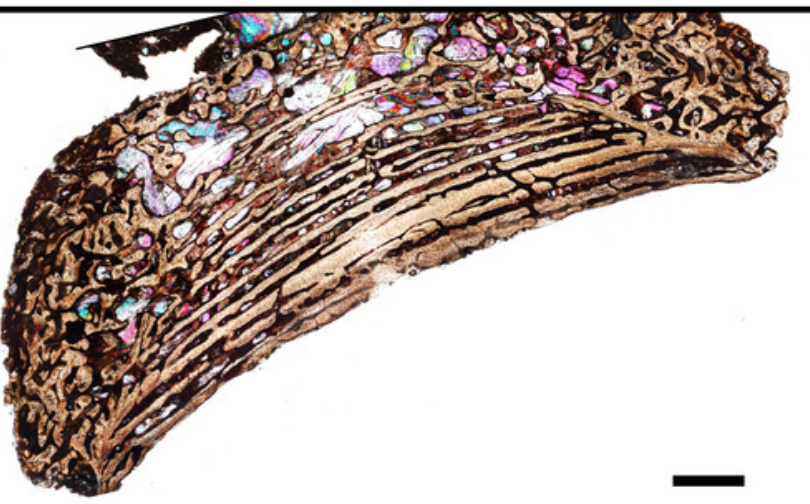

(D)

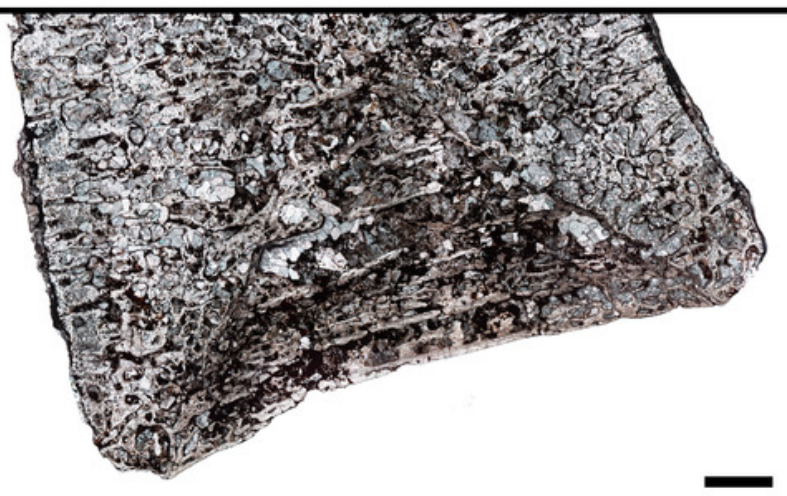


Figure 10

Microphotographs of the dorsal endochondral region in three small specimens in sagittal profile.

(A) PEFO 36874a; (B) PEFO 16696a, (C) PEFO 4826. Scale bars equal to $1 \mathrm{~mm}$. 

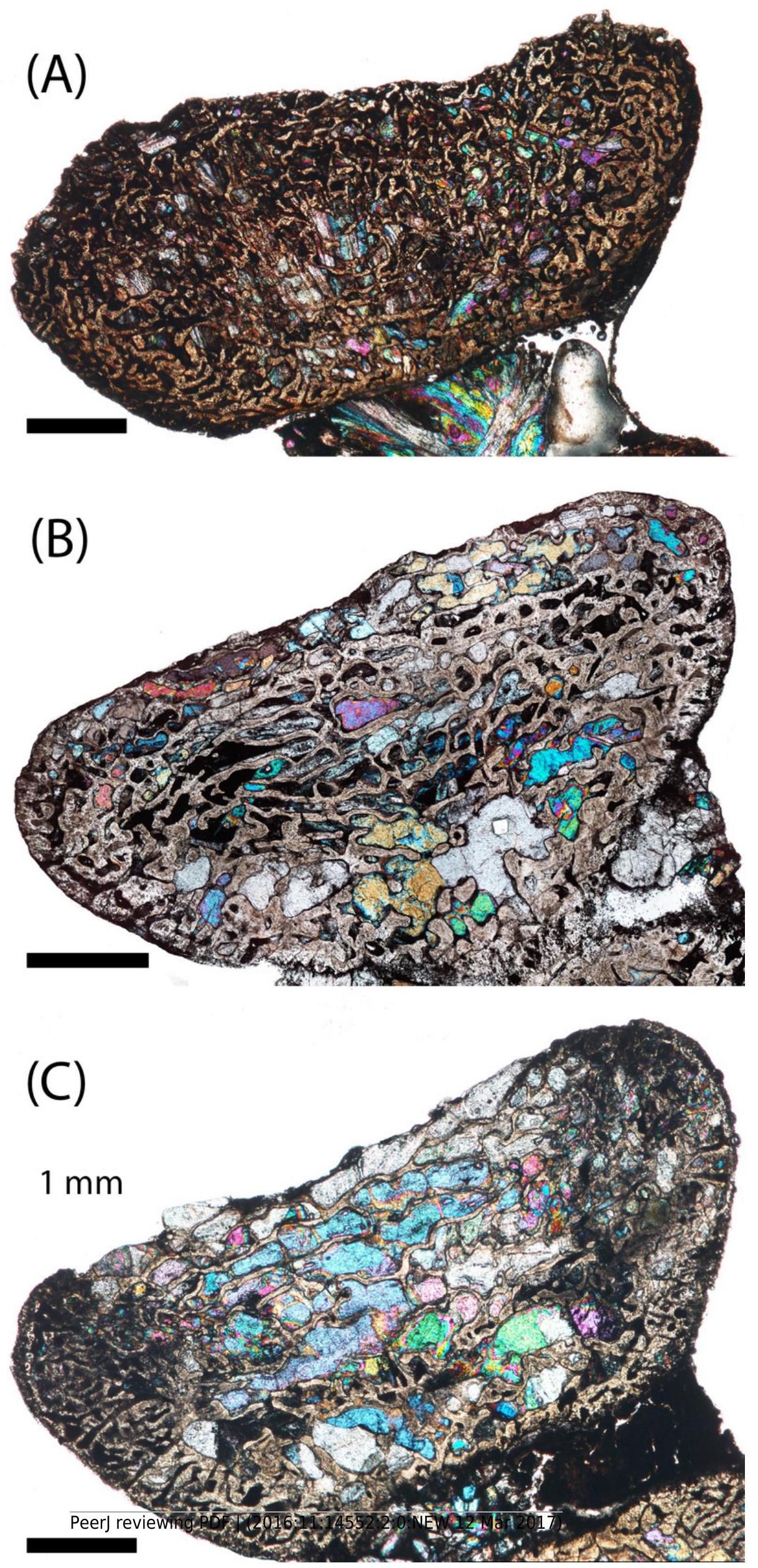


\section{Figure 11}

Microphotographs of the external cortex in large intercentra.

(A) PEFO 38645 in sagittal profile; (B) the same specimen in transverse profile; (C) PEFO 35392a; (D) the same specimen in transverse profile; (E) PEFO 16696c; (F) the same specimen in transverse profile; (G) PEFO 38726; $(\mathrm{H})$ the same specimen in transverse profile. Arrows indicate the position of the LAGs in PEFO 38726. Abbreviation: $a=$ annulus. Scale bars equal to $1 \mathrm{~mm}$. 

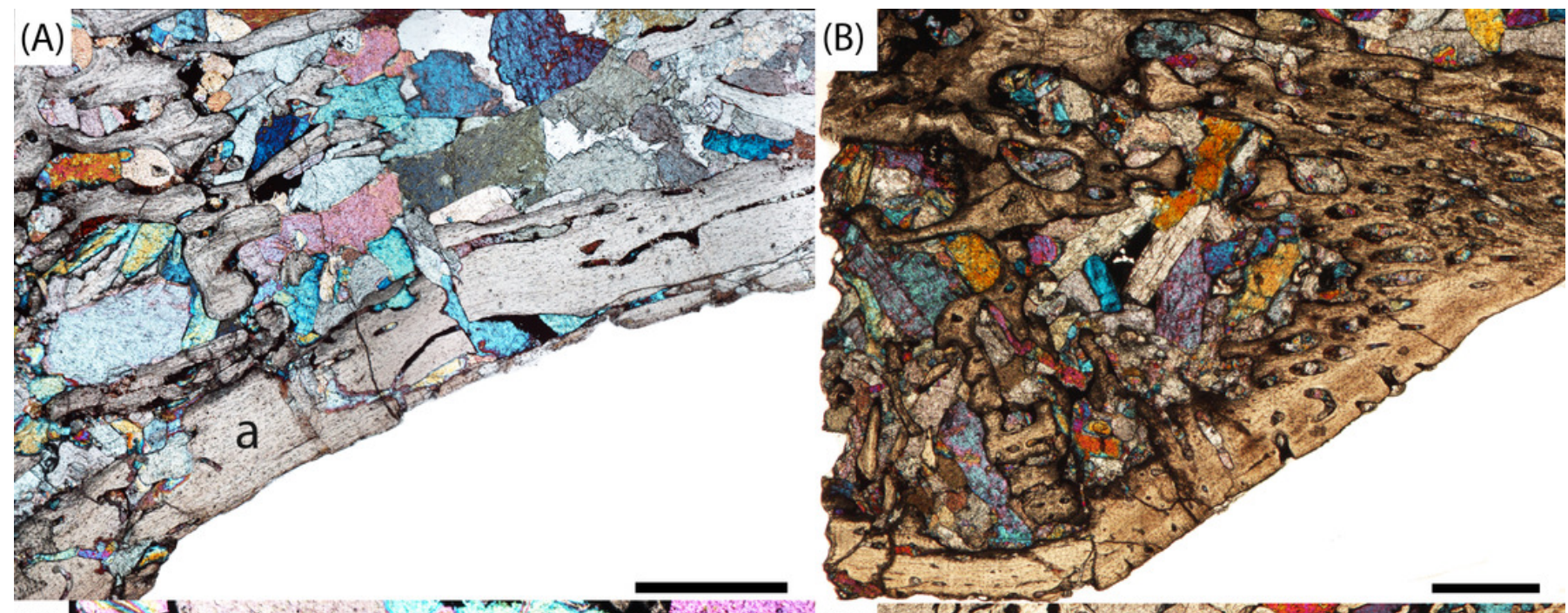

(C) 1

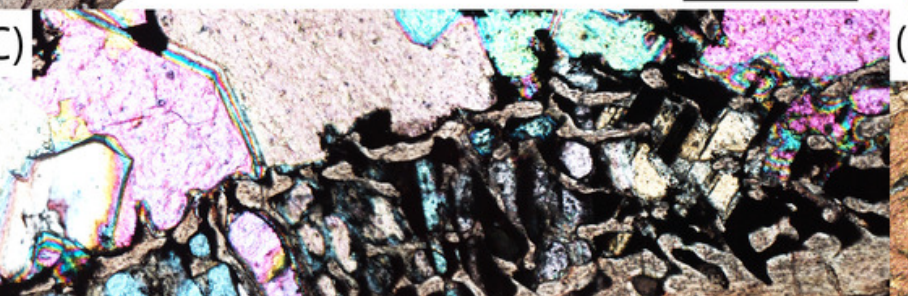

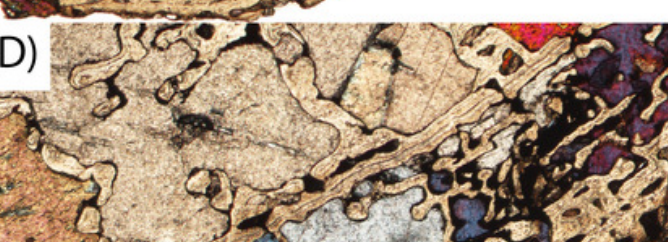

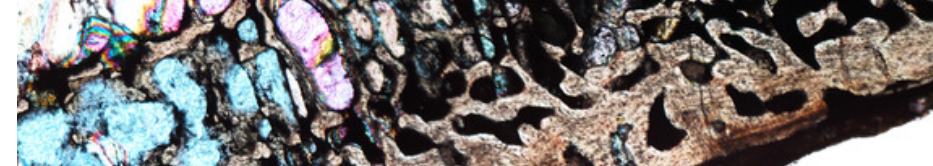

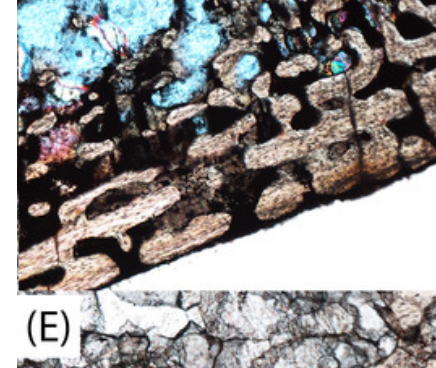

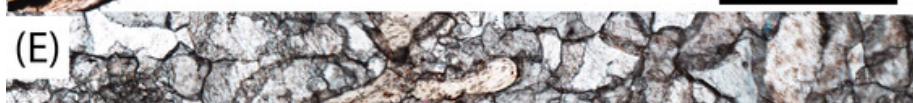

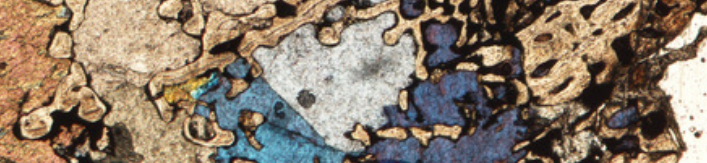
(1)

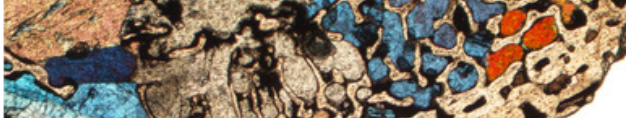
I.

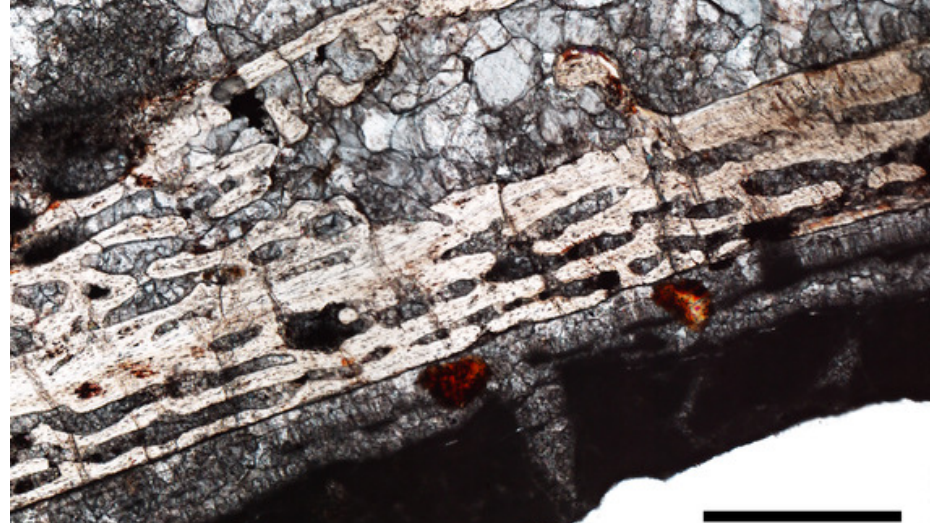

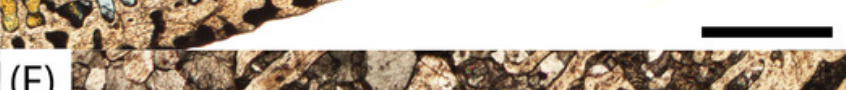

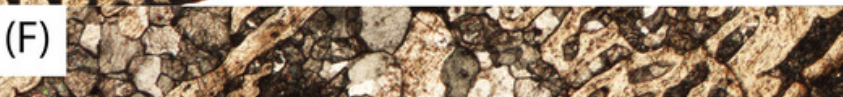

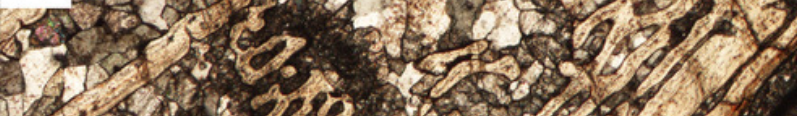

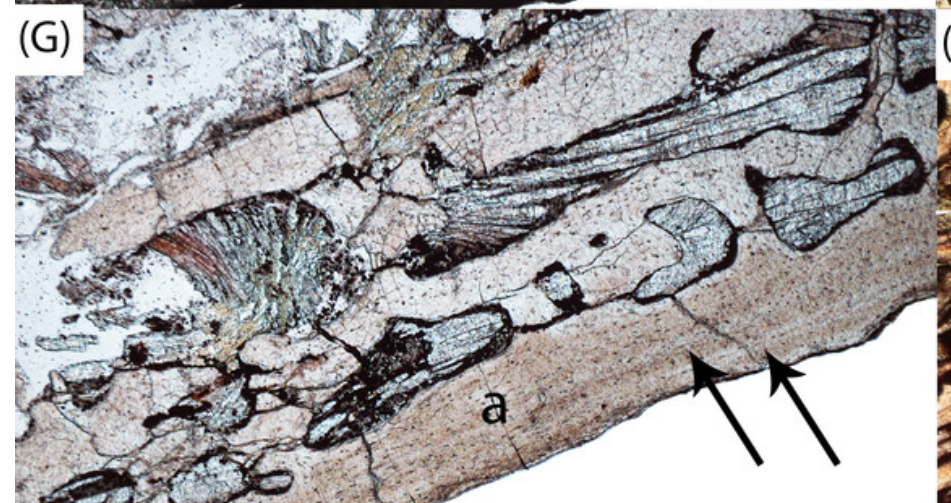

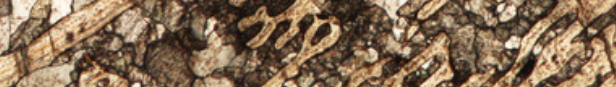
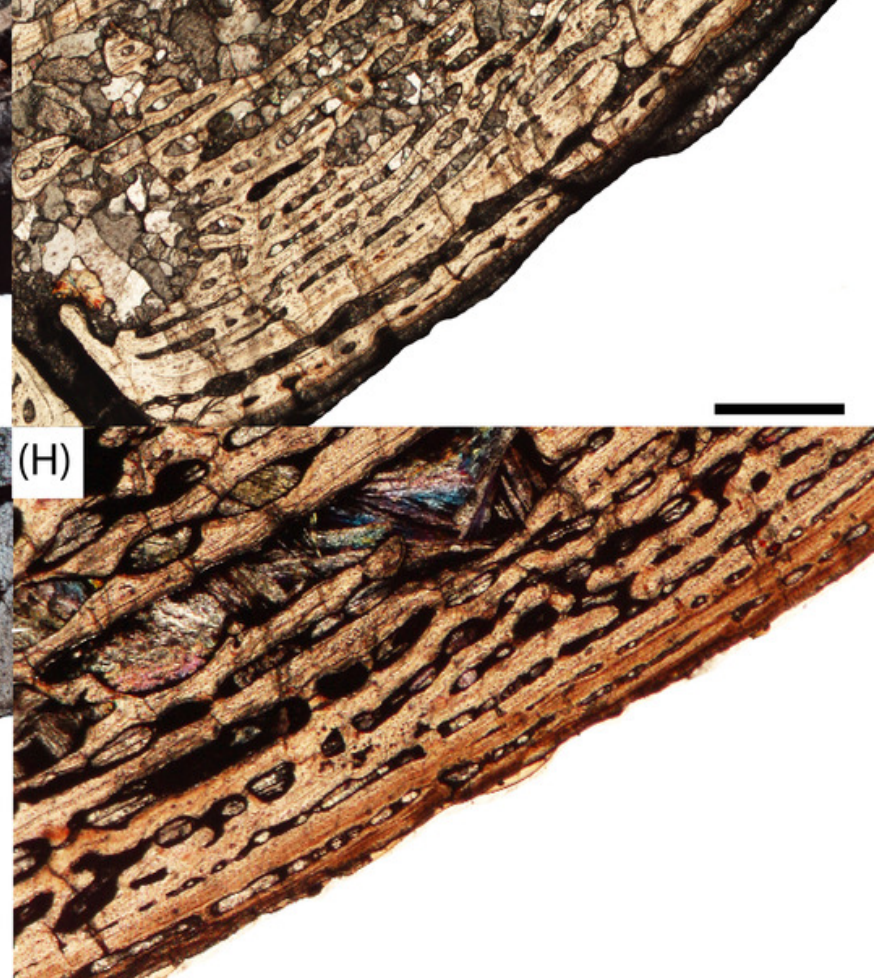

1. Péer reviewing PDF | (2016:11:14552:2:0:NEW 12 Mar 2017) 


\section{Figure 12}

Microphotographs of calcified cartilage and secondary remodeling in transverse profile.

(A) PEFO 36874a in the interior endochondral region; (B) calcified cartilage in the same specimen in polarized light; (C) PEFO 35392b in the inner endochondral region; (D) calcified cartilage in the same specimen in polarized light; (E) PEFO 38726 in the interior endochondral region; (F) absence of calcified cartilage and abundant secondary remodeling in the same specimen in polarized light. Scale bars equal to $100 \mu \mathrm{m}$. 


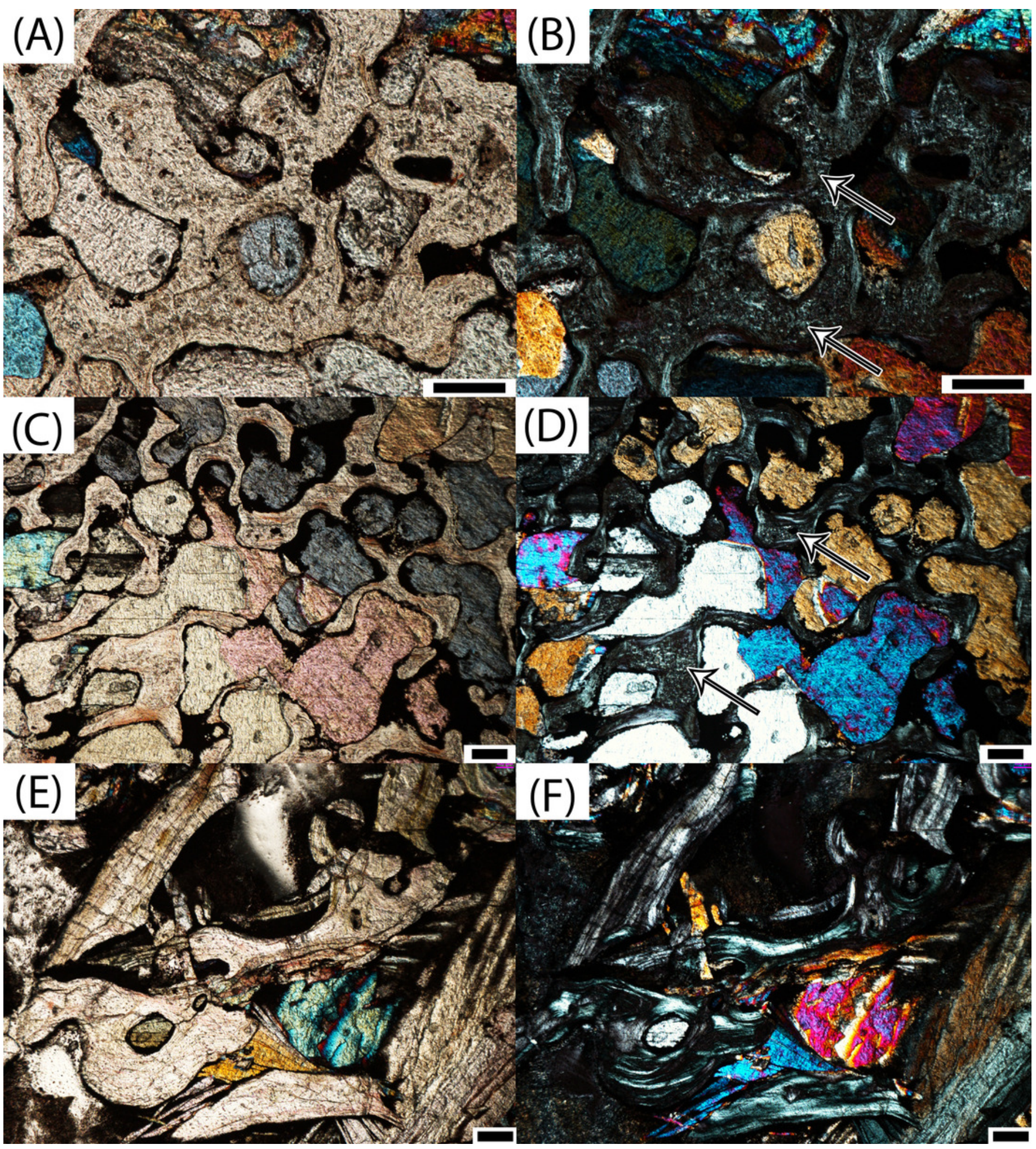




\section{Figure 13}

Microphotographs of nutrient foramina in transverse profile.

(A) nutrient foramen from the ventral periosteal surface PEFO 4826; (B) same specimen in polarized light; (C) nutrient foramen from the lateral surface of PEFO 16696c; (D) same specimen in polarized light; (E) nutrient foramen from the dorsolateral surface of PEFO 36874a; (F) same specimen in polarized light. Scale bars equal to $500 \mu \mathrm{m}$. 

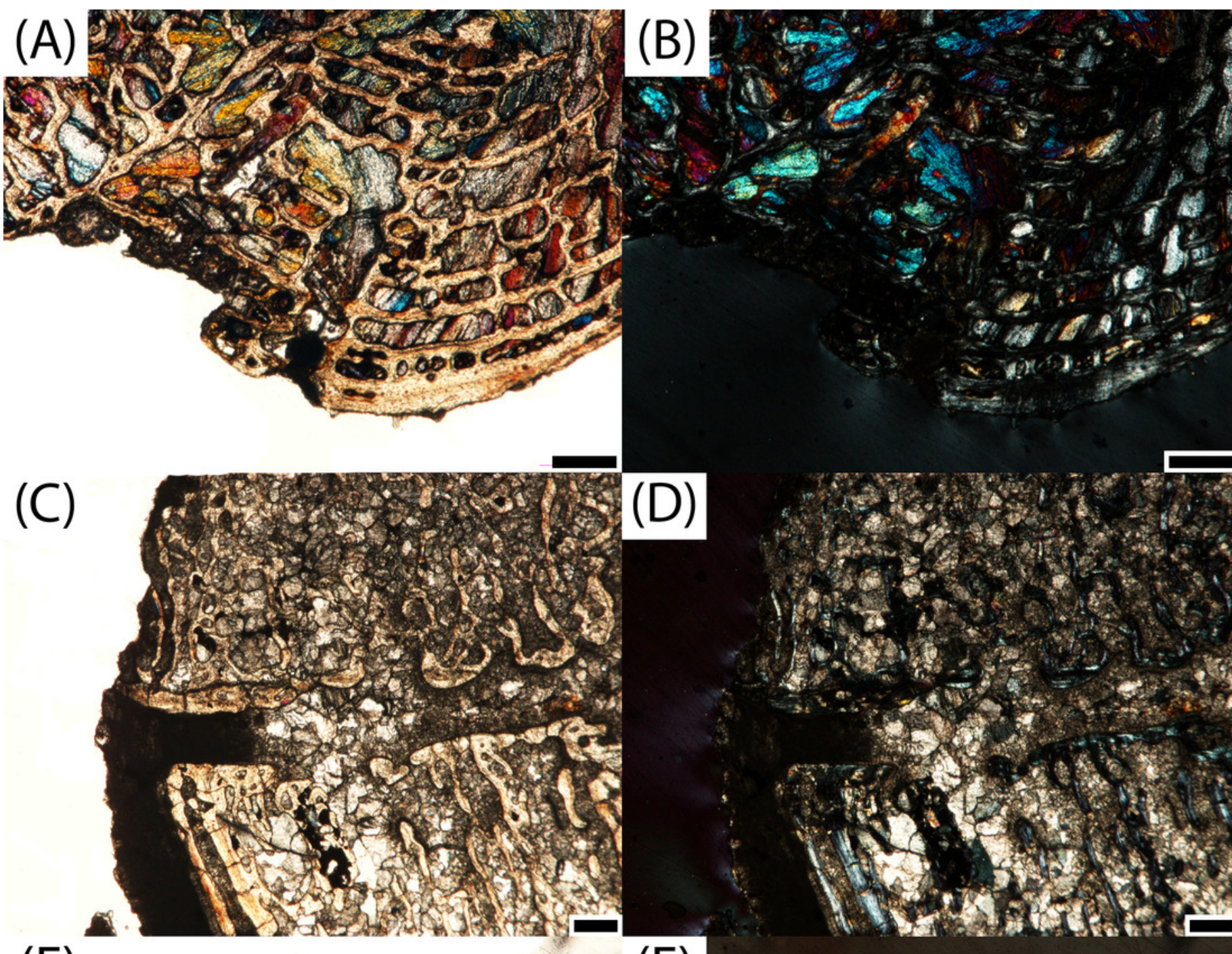

(E)

(F)
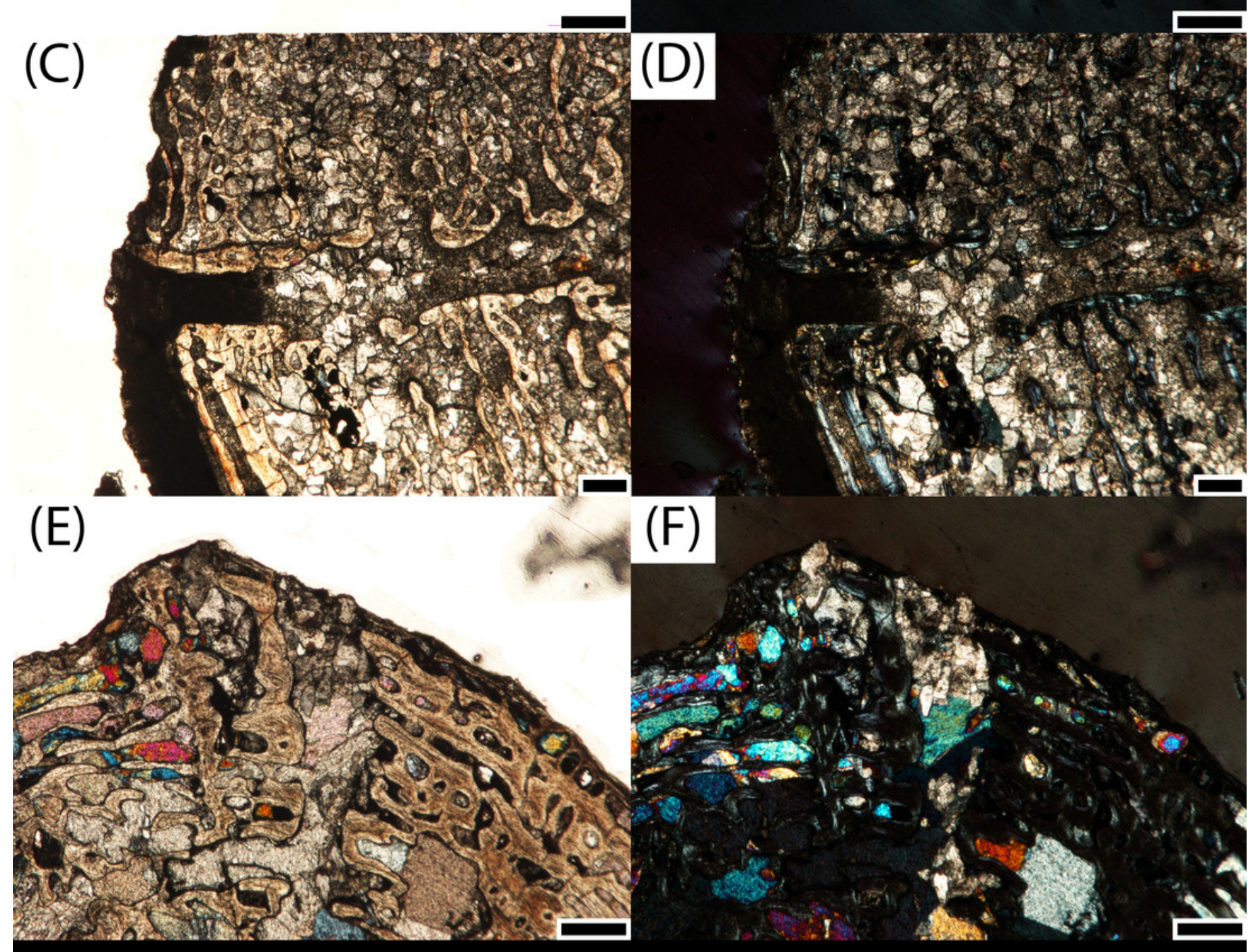


\section{Table $\mathbf{1}$ (on next page)}

Summary of intercentra analyzed in this experiment.

For specimens with multiple elements, the listed order reflects their order by size, from smallest to largest. Letter assignments for multi-element specimens were created for the purpose of this publication to facilitate their references throughout the text. Measurements were performed in the same manner as in Konietzko-Meier, Bodzioch, \& Sander (2012), where length is in the anteroposterior axis, width is in the mediolateral axis, and height is in the dorsoventral axis. Geologic member abbreviations: BMM - Blue Mesa Member; PFM Petrified Forest Member. 
1 Table 1. Summary of intercentra analyzed in this experiment. For specimens with multiple elements,

2 the listed order reflects their order by size, from smallest to largest. Letter assignments for multi-element

3 specimens were created for the purpose of this publication to facilitate their references throughout the

4 text. Measurements were performed in the same manner as in Konietzko-Meier, Bodzioch, \& Sander

5 (2013), where length is in the anteroposterior axis, width is in the mediolateral axis, and height is in the

6 dorsoventral axis. Geologic member abbreviations: BMM-Blue Mesa Member; PFM-Petrified Forest

7 Member.

\begin{tabular}{|c|c|c|c|c|c|c|c|}
\hline $\begin{array}{l}\text { Specimen } \\
\text { number }\end{array}$ & $\begin{array}{l}\text { Estimated } \\
\text { position }\end{array}$ & $\begin{array}{l}\text { Cutting } \\
\text { plane }\end{array}$ & $\begin{array}{l}\text { Length } \\
(\mathrm{mm})\end{array}$ & $\begin{array}{l}\text { Width } \\
(\mathrm{mm})\end{array}$ & $\begin{array}{l}\text { Height } \\
(\mathrm{mm})\end{array}$ & W:L & $\begin{array}{l}\text { Geologic } \\
\text { member }\end{array}$ \\
\hline PEFO 38726 & anterior dorsal & sagittal & 22.98 & 55.32 & 46.91 & 2.40 & BMM \\
\hline PEFO 4826 & dorsal & sagittal & 10.25 & 10.55 & 12.71 & 1.03 & BMM \\
\hline PEFO 38645 & presacral & sagittal & 10.99 & 21.90 & 19.32 & 1.99 & PFM \\
\hline PEFO 36874a & dorsal & sagittal & 7.65 & 10.72 & 8.85 & 1.40 & PFM \\
\hline PEFO $36874 b$ & perisacral & sagittal & 11.85 & 19.63 & 17.25 & 1.65 & PFM \\
\hline PEFO 35392a & mid-dorsal & sagittal & 15.43 & 28.27 & 25.74 & 1.83 & PFM \\
\hline PEFO 35392b & anterior dorsal & sagittal & 15.37 & 25.89 & 24.72 & 1.68 & PFM \\
\hline PEFO 16696a & presacral & sagittal & 8.22 & 10.22 & 9.09 & 1.24 & PFM \\
\hline PEFO $16696 b$ & mid-dorsal & sagittal & 9.52 & 15.96 & 12.11 & 1.67 & PFM \\
\hline PEFO 16696c & mid-dorsal & sagittal & 16.60 & 26.83 & 16.13 & 1.61 & PFM \\
\hline
\end{tabular}

8 


\section{Table 2 (on next page)}

Summary of major histological landmarks identified in the sampled specimens.

For specimens with multiple elements, the listed order reflects their order by size, from smallest to largest. Dots indicate the presence of the structure in specimens. 
1 Table 2. Summary of major histological features identified in the sampled specimens. For specimens 2 with multiple elements, the listed order reflects their order by size, from smallest to largest. Dots indicate 3 the presence of the structure in specimens.

\begin{tabular}{|c|c|c|c|c|c|}
\hline Specimen ID & Periosteal bone & $\begin{array}{l}\text { Decreased vascularization in } \\
\text { external cortex }\end{array}$ & $\begin{array}{l}\text { Compact } \\
\text { annulus }\end{array}$ & LAGs & HOS \\
\hline PEFO 38726 & $\bullet$ & $\bullet$ & $\bullet$ & $\bullet$ & 4 \\
\hline PEFO 4826 & $\bullet$ & & & & 2 \\
\hline PEFO 38645 & $\bullet$ & $\bullet$ & • & & 3 \\
\hline PEFO 36874a & $\bullet$ & & & & 2 \\
\hline PEFO 36874b & $\bullet$ & & & & 2 \\
\hline PEFO 35392a & $\bullet$ & • & & & 3 \\
\hline PEFO 35392b & • & • & & & 3 \\
\hline PEFO 16696a & $\bullet$ & & & & 2 \\
\hline PEFO 16696b & $\bullet$ & & & & 2 \\
\hline PEFO 16696c & - & $\bullet$ & & & 3 \\
\hline
\end{tabular}

4 